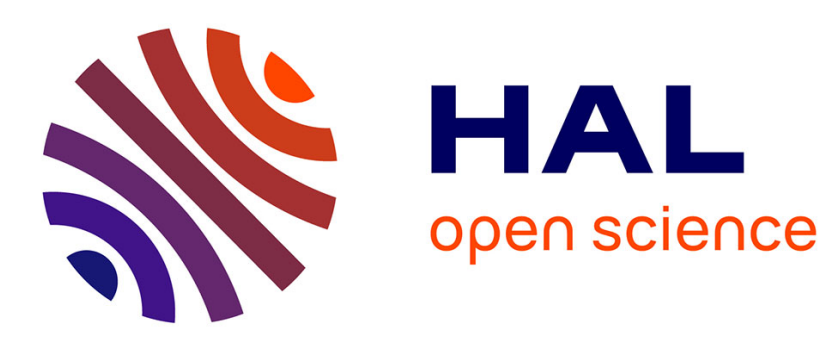

\title{
Central substitution of azacalixphyrins: a strategy towards acidochromic NIR dyes
}

Cloé Azarias, Simon Pascal, Olivier Siri, Denis Jacquemin

\section{To cite this version:}

Cloé Azarias, Simon Pascal, Olivier Siri, Denis Jacquemin. Central substitution of azacalixphyrins: a strategy towards acidochromic NIR dyes. Physical Chemistry Chemical Physics, 2018, 20 (30), pp.20056-20069. 10.1039/c8cp03789b . hal-01958594

\section{HAL Id: hal-01958594 \\ https://hal.science/hal-01958594}

Submitted on 31 Jan 2020

HAL is a multi-disciplinary open access archive for the deposit and dissemination of scientific research documents, whether they are published or not. The documents may come from teaching and research institutions in France or abroad, or from public or private research centers.
L'archive ouverte pluridisciplinaire HAL, est destinée au dépôt et à la diffusion de documents scientifiques de niveau recherche, publiés ou non, émanant des établissements d'enseignement et de recherche français ou étrangers, des laboratoires publics ou privés. 


\title{
Central substitution of azacalixphyrins: a strategy to acidochromic NIR dyes ${ }^{\dagger}$
}

\begin{abstract}
Cloé Azarias, ${ }^{a}$ Simon Pascal, ${ }^{b}$ Olivier Siri, ${ }^{* b}$ and Denis Jacquemin ${ }^{* a}$
Azacalixphyrin derivatives constitute one of the most intriguing class of macrocyclic compounds. Indeed, these isostructural and isoelectronic analogues of porphyrins intensively absorb light up to the near infrared region, exist under several tautomeric forms and present a bis-zwitterionic structure, with a central dianionic core surrounded by positively-charged trimethine cyanines. However, the control of the position of the absorption bands of azacalixphyrin remains an important challenge, as the experimental attempts reported to date have led to very modest auxochromic shifts only. Inspired by previous works demonstrating that the optical signatures of cyanines can be strongly modified by using central substituents, we have evaluated the validity of this strategy for azacalixphyrin considering several substituents positioned in symmetric or asymmetric manners around the core and linked through both single and double bonds, as well as several protonation states of the macrocycles. It turns out that bromine and dimethylamino substituents have a negligible or weak impact on the optical properties of azacalixphyrins with maximal redshifts smaller than $0.10 \mathrm{eV}$. The imino substitution induces strong geometrical deformations that counterbalance the electronic effects leading to rather modest variations of the optical signatures. In contrast, for keto-substituted macrocycles, electronic effects dominate and very strong acidochromic shifts are predicted with absorption wavelengths going from 811 to $1095 \mathrm{~nm}$ upon double deprotonation.
\end{abstract}

\section{Introduction}

$\pi$-conjugated macrocyclic derivatives constitute one of the most important classes of organic molecules. ${ }^{1-7}$ Indeed, the stability, tunable properties, and ability to complex a large panel of metals have allowed macrocycles to become central building blocks in many research lines of biological, chemical, and material sciences. The hallmark members of the family are, without dispute, porphyrin and phthalocyanine derivatives that stand as the most important and adaptable macrocycles. The unsubstituted porphyrin, porphin, presents four pyrrolic units linked through methine bridges forming a planar 16-membered central ring. Porphyrins possess $22 \pi$-electrons but only $18 \pi$-electrons are delocalised over the macrocycle, hence granting aromaticity according to Hückel's rule. As a consequence, porphyrins present an advantageous chemical stability and peculiar optical properties. More specifically, they absorb light in two different regions of the visible spectrum with weak Q-bands appearing at ca. 500-

\footnotetext{
${ }^{a}$ Chimie Et Interdisciplinarité, Synthèse, Analyse, Modélisation (CEISAM), UMR CNRS no. 6230, BP 92208, Université de Nantes, 2, Rue de la Houssinière, 44322 Nantes, France.E-mail: Denis.Jacquemin@univ-nantes.fr

${ }^{b}$ Aix Marseille Univ, CNRS-CINAM, Campus de Luminy, Case 913, 13288 Marseille Cedex 09, France. E-mail: olivier.siri@univ-amu.fr

$\dagger$ Electronic Supplementary Information (ESI) available: (i) characterisation of the parent ACP; (ii) additional tables and figures for the single-bonded substituted ACPs; and (iii) additional tables and figures for the double-bonded substituted ACPs. See DOI: $10.1039 / \mathrm{b} 000000 \mathrm{x} /$
}

$600 \mathrm{~nm}$ and intense Soret bands peaking at ca. $400 \mathrm{~nm}$. To improve the light absorption properties at long wavelength, one can replace the methine linkers by imine bridges and/or use of isoindole moieties instead of pyrrole units, therefore leading to phthalocyanines. ${ }^{8}$ Another macrocyclic core allowing to obtain a more intense near infrared (NIR) absorption is azacalixphyrin (ACP, see Figure 1). ACPs constitute, the first and, to date, the only "pyrrol-free" isostructural and isoelectronic porphyrin azaanalogues. The first member of this new family is compound $\mathrm{AH}_{2}^{2+}$ (see Figure 1a) that has been first synthesised in 2013 and characterised both experimentally and theoretically by the groups involved in the present investigation. ${ }^{9} \mathbf{A H}_{2}^{2+}$ strongly absorbs in the visible as well as in the UV and NIR regions (between 300 and $1000 \mathrm{~nm}$ ). The term "azacalixphyrin" is actually the concatenation of "azacalixarene" and "porphyrin" (Figure 1b) and has been proposed to underscore the similarities that ACP presents with these two macrocycles. Indeed, the azacalixphyrin is a 16membered macrocycle presenting four nitrogen atoms separated by three carbon atoms, a structural arrangement shared with the two above-mentioned macrocycles. In addition, ACPs are composed of four phenyl-type rings bridged by nitrogen atoms (as in azacalixarenes) while possessing 18- $\pi$ delocalised electrons (as in porphyrins).

Beyond the fact that those macrocycles are easily accessible (straightforward synthesis allowing high versatility), the parent ACP presents unique structural, electronic, optical, and complex- 

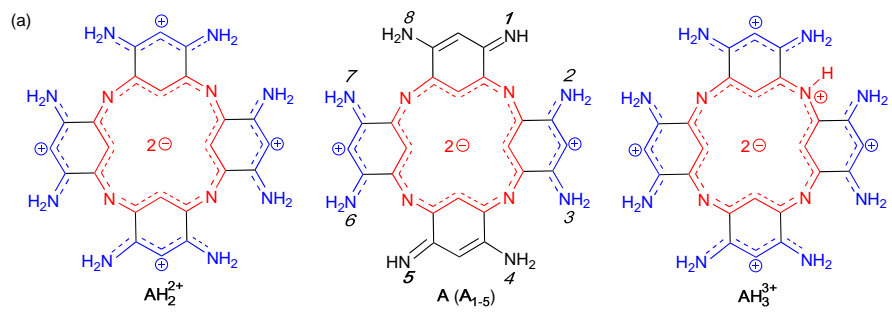

(b)

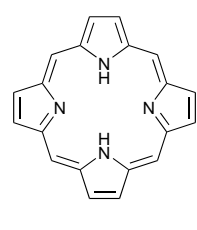

porphyrin

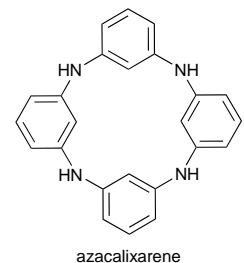

Fig. 1 (a) Representation of the parent azacalixphyrin $\mathbf{A H}_{2}^{2+}$, one of its neutral form $\mathbf{A}$, the 1-5 tautomer, and its bridge-protonated form, $\mathbf{A H}_{3}^{3+}$. (b) Representation of the core skeleton of porphyrin and azacalixarene macrocycles.

ation properties which makes it a very promising platform for applications in a wide range of research fields, ${ }^{9}$ and several developments and analyses of the ACPs have indeed appeared in the last few years. ${ }^{10-14}$ Let us summarise the main findings obtained up to now, starting by the unsubstituted ACP. First, both Density Functional Theory (DFT) and X-Ray Diffraction (XRD) indicate that ACP adopts a saddle-like conformation due to the repulsion of the four central hydrogen atoms, but that the electron delocalisation is high with only two types of bonds (CN and CC) presenting equivalent distance in the macrocyclic core (in red in Figure 1a). This bond equalisation is also found in the four positively charged external subunits (in blue) that clearly present a cyanine character. In contrast the long CC distances (in black) between the external and central moieties indicate ground-state separation between the central and external moieties. Hence the $\mathrm{AH}_{2}^{2+}$ ACP can be viewed as a tetra-protonated dianion or a di-protonated bis-zwitterion, an analysis also consistent with works performed on tetraaminobenzene. ${ }^{15-17}$ A surprising feature of the azacalixphyrin parent, given its zwitterionic nature, is its high chemical stability, i.e., ACP remains stable when exposed to air for months as a solid and for days in solution. ${ }^{9}$ This stability can be rationalised not only by its aromatic nature, as confirmed by the calculated Nucleus Independent Chemical Shift (NICS), but also by showing that the possible hydrolysis mechanisms of ACP are all coming with very high reaction barriers making them kinetically impossible. ${ }^{10}$ Another feature of the ACP, relevant for the present study, is its tautomerism occurring in the neutral form. Indeed, although only one tautomer of the "neutral" ACP A is represented in Figure 1, six non-equivalent tautomers can be drawn depending on the relative positions of the two imine functions. To distinguish these tautomers, a specific nomenclature was proposed: ${ }^{11,12}$ the tautomer denoted $\mathbf{A}_{\mathbf{x}-\mathbf{y}}$ contains two imine functions at positions $\mathbf{x}$ and $\mathbf{y}$. The co-existence of several tautomers in solution was demonstrated by 2D NMR measurements that showed that the protons of the external nitrogen atoms are strongly coupled with those of water for A hinting that very effective chemical exchanges are occurring in this neutral compound. ${ }^{11}$ Furthermore, the DFT calculations indicated that several tautomers can co-exist in solution and that the barriers for solvent-assisted proton transfer were small enough to envisage fast exchange at room temperature. ${ }^{11}$ As stated above, one of the key features of the azacalixphyrin macrocycles is their optical spectrum, e.g., the absorption spectrum of the parent $\mathrm{AH}_{2}^{2+}$ exhibits four main peaks in the visible domain $\left(\lambda_{\max }=409,441\right.$, 492, and $649 \mathrm{~nm}$ ) as well as an additional broad band in the NIR region $\left(\lambda_{\max }=890 \mathrm{~nm}\right) .{ }^{9}$ A rather limited acidochromism was measured: the spectrum of the tri-protonated ACP $\left(\mathrm{AH}_{3}^{3+}\right.$, with a protonation of one nitrogen of the bridge, see Figure 1a) shows slight hyperchromic and bathochromic (ca. $+30 \mathrm{~nm} /-350 \mathrm{~cm}^{-1}$ ) effects compared to $\mathrm{AH}_{2}^{2+}$, whereas the deprotonation leads to a decrease of the intensity of both NIR and visible bands, this effect being slightly more pronounced in the case of the double deprotonation: the A spectrum is blueshifted, in part due to the presence of a blend of $\mathbf{A}_{\mathbf{x}-\mathbf{y}}$ tautomers. ${ }^{11,12}$

Let us now turn towards substituted ACPs. A limit of the unsubstituted ACP is its poor solubility. To circumvent this problem, substituted azacalixphyrins containing alkyl chains at the periphery have been synthesised and characterised both experimentally and theoretically. ${ }^{13}$ The different derivatives considered $\left(\mathrm{BH}_{2}^{2+}-\mathbf{D H}_{2}^{2+}\right)$ are represented in Figure 2 and differ in: (i) the number of alkyl chains (symmetric $R_{1}=R_{2}=$ Alkyl vs. asymmetric $\mathrm{R}_{1}=$ Alkyl, $\mathrm{R}_{2}=\mathrm{H}$ substitutions); (ii) the length of the chains $\left(\mathrm{C}_{4} \mathrm{H}_{9}\right.$ vs. $\left.\mathrm{C}_{8} \mathrm{H}_{17}\right)$; and (iii) their spatial arrangement (branched vs. linear chains). These derivatives present similar features as the parent $\mathrm{AH}_{2}^{2+}$ in terms of global shape, aromaticity, redox and optical properties though the NIR absorption band undergoes very small redshifts when the number of alkyl substituents is increased. Indeed, going from the unsubstituted parent $\mathrm{AH}_{2}^{2+}\left(\lambda_{\max }=879 \mathrm{~nm}\right)$ to the di-alkylated molecule $\mathbf{C}_{\mathrm{a}} \mathbf{H}_{2}^{2+}$ $\left(\lambda_{\max }=885 \mathrm{~nm}\right)$ and next to the tetra-alkylated azacalixphyrin $\mathrm{CH}_{2}^{2+}\left(\lambda_{\max }=890 \mathrm{~nm}\right)$, small successive bathochromic displacements are observed in methanol solutions. More strikingly, the length of the alkyl chain was found to have a crucial impact on the self-assembly properties. Indeed, only the ACPs possessing four $\mathrm{C}_{8}$ chains, namely $\mathrm{DH}_{2}^{2+}$, were able to form molecular ribbons. ${ }^{13}$ To explore further strategies allowing to modulate the optical properties of the azacalixphyrin, two theoretical investigations were performed at Time-Dependent DFT (TD-DFT) level, for putative $\mathrm{N}$-arylated and metal-complexed ACPs. ${ }^{12,14}$ For the former, redshifts of the NIR band of up to ca. $50 \mathrm{~nm}$ are predicted by theory. ${ }^{12}$ For the latter, metallation of the core of the ACP was shown to possibly lead to a Jahn-Teller-like distortion and significant changes of the optical band, ${ }^{14}$ though such structures remain to be experimentally obtained.

In the present article, we use a palette of theoretical approaches to assess a new strategy for tuning the optical properties of the ACP. Indeed, by taking advantage of the external cyanine-like subsystems of the ACP, we investigate the impact of adding different groups on the central carbon atom (so-called $\mathrm{Y}$ position, see Figure 3 for the investigated systems). This substitution pattern is inspired by a previous work focussed on polymethine dyes, ${ }^{18}$ in which it was demonstrated that placing different electroactive 

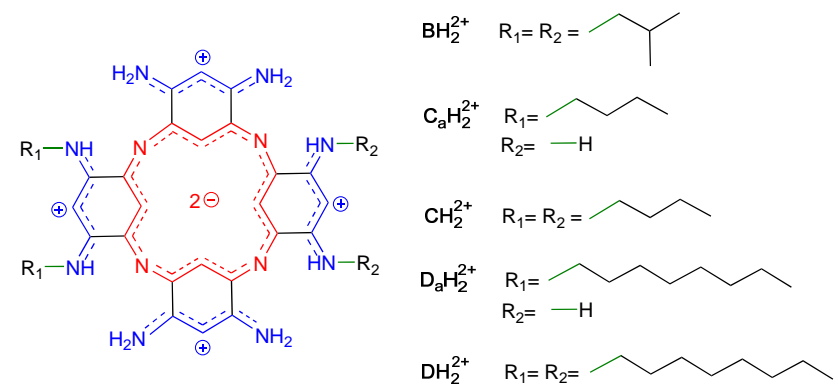

Fig. 2 Structure of $\mathrm{N}$-alkylated azacalixphyrins in their di-protonated forms synthesised and characterised in Ref. 13. The index a indicates that the ACP is asymmetrically substituted, i.e., at positions $R_{1}$ only.

groups on the central carbon atom can drastically modify their ground state electronic configuration and subsequently tune their absorption spectrum over the whole visible and near-infrared spectral ranges. In Scheme S1 in the ESI we propose a possible synthetic approach to obtain Y-substituted derivatives, this route is based on the syntheses of both ACP and polymethines. ${ }^{9,13,18}$ Our goal here is to propose new ACP substitution patterns allowing to control the position of the NIR band over a wider range of wavelengths than performed to date. This is why we selected the $\mathbf{Y}$ position. Indeed, in a previous work, ${ }^{18}$ this substitution was reported to deliver two very different behaviours, i.e., intense, sharp, and non-solvatochromic cyanine-type bands for $\mathbf{Y}=\mathrm{SPh}, \mathrm{Br}$, $\mathrm{Cl}, \mathrm{OAc}, \mathrm{OPh}$, and $\mathrm{H}$ (single bond group), and hypochromic and broader adsorption bands covering the visible domain (400-800 $\mathrm{nm}$ ) when $\mathbf{Y}$ is an amino, imino, keto, and malonitrile function (double bond group for the three latter).
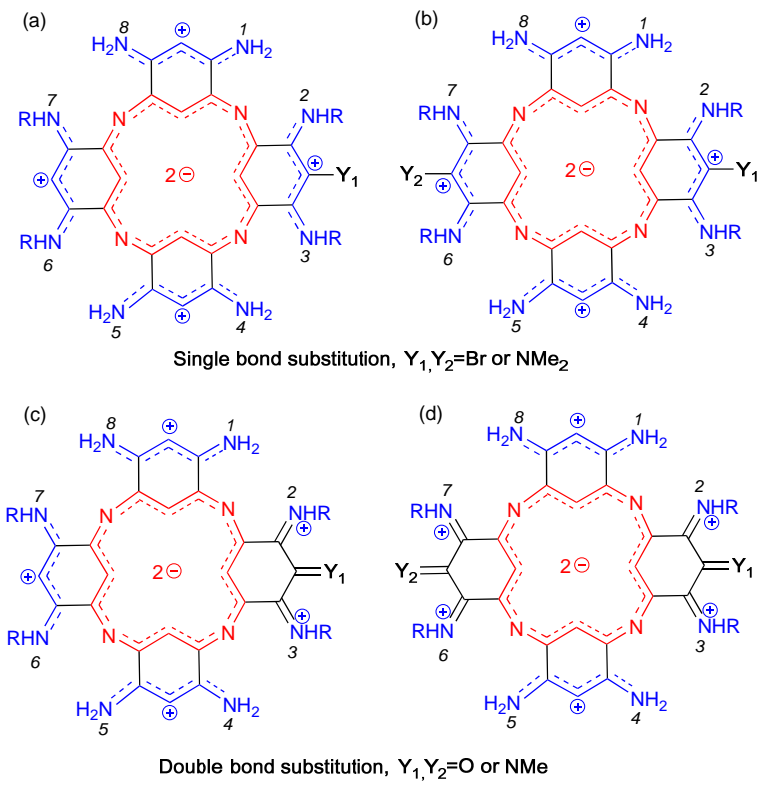

Fig. 3 Representation of the compounds investigated here with asymmetric (left) and symmetric (right) Y-substituted ACPs using substituents with single (top) and double (bottom) bonds. For all compounds, we represent the fully protonated forms for which a single tautomer exists. $\mathrm{R}=\mathrm{Et}$ except when noted.

\section{Computational approach}

All DFT and TD-DFT calculations have been achieved using the Gaussian16 program. ${ }^{19}$ Geometry optimisation and frequency calculations have been performed at the PBE0/6-31G(d) level of theory. The self-consistent field $\left(10^{-10}\right.$ a.u.) and geometry optimisation $\left(10^{-5}\right.$ a.u.) convergence thresholds have been tightened and the $(99,590)$ pruned integration grid (the so-called ultrafine grid) has been used. This level of theory was showed to provide ground state (GS) structures fitting well experiment for ACP. ${ }^{9}$ DFT Hessian were computed to confirm the nature (minima) of all GS geometries and to access to the free energy $(G)$ of each structures, which is important to assess the possible co-existence of several tautomers. For some systems, these geometries were used to determine the HOMA (Harmonic oscillator model of aromaticity) parameters that provides a structural measure of aromaticity. ${ }^{20}$ On the basis of the optimised geometries, we computed: (i) the NICS(0) determined in gas phase at the PBE0/cc-pVTZ level of theory; ${ }^{21,22}$ (ii) the total and transition energies using the $\mathrm{PBE}^{23,24}$, M06-2X, ${ }^{25}$ and CAM-B3LYP ${ }^{26}$ exchange-correlation functionals (XCF) in combination with a larger atomic basis set (LBS), 6-311+G(2d,p). Except when explicitly noted, the solvent (DMSO) has been accounted in all the calculations by using the polarisable continuum model (PCM) ${ }^{27}$ approach in its linearresponse (LR) ${ }^{28,29}$ form, under its non-equilibrium limit for the calculations of transition energies.

For the protonated species of the ACP parent $\left(\mathrm{AH}^{+}, \mathrm{AH}_{2}^{2+}\right.$, and $\mathrm{AH}_{3}^{3+}$ ), the transition and 0-0 energies have been additionally evaluated using several methods. A procedure equivalent to the one described above for the GS geometry optimisation and Hessian calculations has been applied for the first excited state of (protonated) ACPs, that is, PCM-TD-PBE0/6-31G(d). On these optimised geometries, we used the Dunning aug-cc-pVDZ atomic basis set and computed: (i) the gas-phase and PCM TD-DFT transition energies with the three same functionals as above; (ii) the gas-phase $\mathrm{ADC}(2)^{30}$ and $\mathrm{CC} 2^{31}$ transition energies, using the Turbomole code; ${ }^{32}$; and (iii) the gas-phase $\mathrm{BSE} / \mathrm{evGW}$ transition energies ${ }^{33}$ using the Fiesta package. ${ }^{34}$ For the BSE calculations, the input DFT eigenstates were generated with the NWChem package $^{35}$ with the same three DFT functionals. Five occupied and five virtual DFT levels were explicitly corrected using the socalled evGW approach, all the other DFT occupied/unoccupied states being rigidly shifted according to the $G W$ correction obtained for the lowest/highest corrected levels. This choice is justified by test calculations carried out to assess the impact of the number of occupied/virtual energy levels explicitly corrected at the evGW level, on the transition energies of $\mathrm{AH}_{2}^{2+}$.

\section{Results and discussion}

\subsection{Benchmarks for the parent ACP}

Although calculations on the parent ACP system were previously reported by our groups, ${ }^{9-12}$ we provide in the ESI a detailed characterization of it, as this allows direct comparisons with the Ysubstituted macrocycles that are treated herein. A key methodological aspect that was never considered previously however is the reliability of TD-DFT for simulating the spectral properties 
Table 1 Gas-phase $\mathrm{CC}$, ADC(2), TD-DFT, and BSE/evGW vertical transition energies (in eV) and oscillator strengths ( $f$, in parentheses) of the first four excited states of the protonated ACP parents. All the transition energies have been computed using the aug-cc-pVDZ basis set on the geometry optimised at the PCM(DMSO)-PBE0/6-31G(d) level. For the di-protonated species, the two first excited states $\left(\mathrm{S}_{1}\right.$ and $\left.\mathrm{S}_{2}\right)$ are degenerated so that only one energy is reported for these two states and the oscillator strength given is the sum of the oscillator strengths of the two degenerated states. The same holds for $\mathrm{S}_{3}$ and $\mathrm{S}_{4}$ states. CAM, MAD, MaxAD and MinAD stand for CAM-B3LYP, Mean Absolute Deviation, Maximal Absolute Deviation and Minimal Absolute Deviation, respectively. All statistical data are determined using CC2 as a reference.

\begin{tabular}{c|c|c|ccc|ccc}
\hline Molecule & gas-CC2 & gas-ADC(2) & gas-TD-DFT & \multicolumn{3}{c}{ gas-BSE/evGW@ } \\
& & & PBE0 & M06-2X & CAM & PBE0 & M06-2X \\
\hline $\mathrm{AH}^{+}$ & $1.431(0.09)$ & $1.194(0.06)$ & $1.296(0.04)$ & $1.466(0.09)$ & $1.434(0.10)$ & $1.268(0.04)$ & $1.244(0.07)$ & $1.224(0.07)$ \\
& $1.496(0.03)$ & $1.309(0.04)$ & $1.507(0.03)$ & $1.661(0.02)$ & $1.649(0.02)$ & $1.389(0.03)$ & $1.402(0.02)$ & $1.397(0.02)$ \\
& $1.917(0.18)$ & $1.695(0.22)$ & $1.860(0.19)$ & $2.103(0.27)$ & $2.122(0.31)$ & $1.715(0.06)$ & $1.794(0.19)$ & $1.784(0.21)$ \\
& $2.007(0.31)$ & $1.846(0.33)$ & $2.121(0.23)$ & $2.210(0.17)$ & $2.250(0.17)$ & $1.841(0.22)$ & $1.892(0.19)$ & $1.867(0.17)$ \\
\hline $\mathrm{AH}_{2}^{2+}$ & $1.646(0.12)$ & $1.595(0.12)$ & $1.573(0.06)$ & $1.597(0.12)$ & $1.537(0.12)$ & $1.313(0.10)$ & $1.364(0.10)$ & $1.350(0.08)$ \\
& $2.139(0.62)$ & $2.075(0.80)$ & $2.127(0.56)$ & $2.257(0.62)$ & $2.271(0.62)$ & $1.824(0.44)$ & $1.937(0.54)$ & $1.926(0.54)$ \\
\hline $\mathrm{AH}_{3}^{3+}$ & $1.592(0.03)$ & $1.358(0.26)$ & $1.555(0.01)$ & $1.569(0.21)$ & $1.515(0.21)$ & $1.269(0.16)$ & $1.315(0.16)$ & $1.301(0.16)$ \\
& $1.609(0.22)$ & $1.442(0.05)$ & $1.592(0.16)$ & $1.667(0.03)$ & $1.629(0.03)$ & $1.357(0.03)$ & $1.413(0.02)$ & $1.403(0.02)$ \\
& $2.092(0.22)$ & $1.886(0.24)$ & $2.047(0.19)$ & $2.203(0.27)$ & $2.222(0.27)$ & $1.804(0.18)$ & $1.902(0.23)$ & $1.890(0.23)$ \\
& $2.129(0.07)$ & $1.996(0.01)$ & $2.130(0.08)$ & $2.319(0.05)$ & $2.339(0.05)$ & $1.919(0.03)$ & $2.007(0.05)$ & $1.996(0.05)$ \\
\hline MAD & - & 0.15 & 0.05 & 0.11 & 0.13 & 0.25 & 0.19 & 0.20 \\
MinAD & - & 0.05 & 0.00 & 0.02 & 0.00 & 0.11 & 0.09 \\
MaxAD & - & 0.24 & 0.14 & 0.20 & 0.24 & 0.33 & 0.28 \\
\hline
\end{tabular}

Table 2 CC2, ADC(2), TD-DFT, and BSE/evGW 0-0 energies (in eV) of the mono-, di-, and tri-protonated azacalixphyrins. The experimental values were extracted from Ref. 9. See caption of Table 1 for more details.

\begin{tabular}{|c|c|c|c|c|c|c|c|c|c|c|}
\hline & \multicolumn{2}{|c|}{ Exp. } & \multicolumn{2}{|c|}{ Wavefunction } & \multicolumn{3}{|c|}{ TD-DFT } & \multicolumn{3}{|c|}{ BSE/evGW@ } \\
\hline & $\lambda_{\max }^{\exp }$ & $\lambda_{\text {foot }}^{\exp }$ & CC2 & $\mathrm{ADC}(2)$ & PBE0 & M06-2X & CAM & PBE0 & M06-2X & CAM \\
\hline $\mathrm{AH}^{+}$ & 1.368 & 1.127 & 1.294 & 0.992 & 1.310 & 1.356 & 1.312 & 1.188 & 1.091 & 1.074 \\
\hline $\mathrm{AH}_{2}^{2+}$ & 1.393 & 1.210 & 1.391 & 1.366 & 1.411 & 1.432 & 1.372 & 1.109 & 1.165 & 1.147 \\
\hline $\mathrm{AH}_{3}^{3+}$ & 1.342 & 1.127 & 1.279 & 0.935 & 1.370 & 1.400 & 1.351 & 1.054 & 1.094 & 1.083 \\
\hline \multicolumn{11}{|c|}{ Difference with respect to the CC2 results } \\
\hline $\mathrm{AH}^{+}$ & & & & 0.30 & 0.02 & 0.06 & 0.02 & 0.11 & 0.20 & 0.22 \\
\hline $\mathbf{A H}_{2}^{2+}$ & & & & 0.03 & 0.02 & 0.04 & 0.02 & 0.28 & 0.23 & 0.24 \\
\hline $\mathrm{AH}_{3}^{\frac{2}{3}+}$ & & & & 0.34 & 0.09 & 0.12 & 0.07 & 0.23 & 0.19 & 0.20 \\
\hline
\end{tabular}

of ACP. Indeed, all studies performed up to now were "limited" to standard vertical TD-DFT calculations. Considering the three protonated forms of the ACP parent, i.e., $\mathrm{AH}^{+}, \mathrm{AH}_{2}^{2+}$, and $\mathrm{AH}_{3}^{3+}$, that present a unique tautomeric form, we compare here for the first time the spectra simulated with TD-DFT using three different exchange-correlation functionals (PBE0, M06-2X, and CAMB3LYP) to the data obtained with post-Hartree-Fock, ADC(2), and CC2, and post-DFT, BSE/evGW theories. We first perform a benchmark study on the gas-phase transition energies of the first four excited states of the protonated ACPs, as these states are involved in the two first absorption bands $\left(S_{1}\right.$ and $S_{2}$ for the NIR band at ca. $900 \mathrm{~nm}$, and $S_{3}$ and $S_{4}$ for the band at ca. $600 \mathrm{~nm}$ ), taking CC2 as reference. CC2 stands as the most refined computational approach that is computationally affordable for these compounds. The results are reported in Table 1. Regarding first the transition energies provided by $\mathrm{ADC}(2)$, it turns out that they are systematically redshifted compared to CC2 with a MAD of $0.15 \mathrm{eV}$. Such underestimation of ADC(2) for low-lying transition is rather usual. ${ }^{36}$ The same underestimation trend is obtained with BSE/evGW, that yields rather large MADs (of 0.25, 0.19, and $0.20 \mathrm{eV}$, starting with the PBE0, M06-2X, and CAM-B3LYP eigenstates, respectively). This is a quite unexpected result, as BSE is known to be suited for cyanine derivatives. ${ }^{33,37}$ Interestingly, the results obtained with TD-DFT better match the CC2 ones, PBE0 performing particularly well with a MAD of $0.05 \mathrm{eV}$ and a maximal deviation of $0.14 \mathrm{eV}$. However, it is worth underlying here that: (i) TD-DFT does not provide a systematic error, i.e., the energies are not all under- or overestimated compared to CC2; (ii) as expected, the XCF dependency is attenuated when using the BSE/eVGW approach, with a maximal absolute deviation between the three XCFs that is twice smaller $(0.07 \mathrm{eV})$ than with TD-DFT (0.14 eV).

Second, to allow more physically well-grounded comparisons with experiment, 0-0 energies $\left(E^{0-0}\right)$ are determined. As the ACP does not fluoresce, the experimental 0-0 energy, usually chosen as the crossing point between absorption and emission curves, ${ }^{36,38}$ is taken here as comprised between the maximal absorption wavelengths $\lambda_{\max }^{\exp }$ and the foot $\lambda_{\text {foot }}^{\exp }$ of the NIR absorption band. Both values are reported in Table 2 and one notes that the experimental AFCP of the di-protonated ACP is expected to be larger than its mono- and tri-protonated counterparts. While the foot of the NIR band of the two latter forms appears at the same energy, the trend observed for their absorption maximum, i.e., $\lambda_{\max }^{\exp }\left(\mathrm{AH}_{3}^{3+}\right)<\lambda_{\max }^{\exp }\left(\mathrm{AH}^{+}\right)$, suggests that the 0-0 energy of $\mathbf{A H}^{+}$ is slightly larger than in its tri-protonated counterpart. Alike the $\lambda_{\max }^{\exp }$ that present a maximal difference of $0.05 \mathrm{eV}$ between the three protonated species, the $\lambda_{\text {foot }}^{\exp }$ also exhibit very small discrepancies, as they all lie within a $0.08 \mathrm{eV}$ window. Table 2 reports the 0-0 energies of $\mathbf{A H}^{+}, \mathbf{A H}_{2}^{2+}$, and $\mathrm{AH}_{3}^{3+}$ obtained with several theoretical approaches. Following Ref. 36, we computed the 00 energies using the gas-phase adiabatic energies of the selected approach (X), corrected for vibrational and solvation effects as 
given by TD-DFT,

$$
\begin{aligned}
E_{\mathrm{X}}^{0-0}(\mathrm{PCM}) & =E_{\mathrm{X}}^{\text {adia }}(\text { gas })+\Delta E^{\mathrm{ZPVE}}(\mathrm{PCM}) \\
& +E_{\mathrm{TD}-\mathrm{DFT}}^{\text {adia }}(\mathrm{PCM})-E_{\mathrm{TD}-\mathrm{DFT}}^{\mathrm{adia}}(\text { gas })
\end{aligned}
$$

Comparing first the experimental data with the CC2 results, that actually stand as our theoretical best estimates, we notice that the CC2 values are systematically comprised within the $\left[\lambda_{\max }^{\exp }-\lambda_{\text {foot }}^{\exp }\right]$ window and that they do not differ from one species to an other by more than $0.11 \mathrm{eV}$, in agreement with the experiments. In addition, the CC2 0-0 energies are increasing following: $\mathrm{AH}_{3}^{3+}<$ $\mathrm{AH}^{+}<\mathrm{AH}_{2}^{2+}$, a ranking consistent with the experimental trend. Concerning the ADC(2) approach, it turns out that it provides too small energies for the mono- and tri-protonated species (below 1 eV) confirming the underestimation trend noted for vertical energies. In addition, the maximal energy difference between the 0 - 0 energies of the three forms of the ACP attains $0.43 \mathrm{eV}$ which clearly does not fit experiments. As observed above for the gasphase vertical energies, BSE/evGW also yields too small transition energies compared to both experiment and CC2. Turning now to the TD-DFT 0-0 energies, one notices that all XCF provide similar results, with deviations from one XCF to another as small as $0.05-0.06 \mathrm{eV}$. Compared to the measurements, all the TD-DFT values fall inside the experimental $\left[\lambda_{\max }^{\exp }-\lambda_{\text {foot }}^{\exp }\right]$ window for the mono-protonated structure, while only the CAM-B3LYP energies are comprised in this energetic window for both $\mathrm{AH}_{2}^{2+}$ and $\mathrm{AH}_{3}^{3+}$. In all cases, the parent $\mathrm{AH}_{2}^{2+}$ macrocycle shows the largest 0-0 energies but the trend between $\mathrm{AH}^{+}$and $\mathrm{AH}_{3}^{3+}$ is reversed compared to CC2. For a given functional, consistently with the experimental trends, the optical signatures of the ACP are almost unaffected by the protonation state (with a maximal range of variations of $0.10,0.08$, and $0.06 \mathrm{eV}$ for PBE0, M06-2X, and CAM-B3LYP, respectively). Interestingly, a good agreement between TD-DFT and CC2 energies is also obtained, in particular with both PBE0 and CAM-B3LYP XCF that both deliver maximal absolute deviations smaller than $0.1 \mathrm{eV}$.

In short, one can state that both TD-PBE0 and TD-CAM-B3LYP stand as reasonable compromises between accuracy and computational cost, at least at this stage. Therefore, in the following, we mainly use PBE0 and checked the results with CAM-B3LYP and/or CC2 when a strong charge-transfer (CT) character was detected.

\subsection{Single-bonded Y substituents}

In this Section, we present an investigation of Y-substitution for substituents linked to the central carbon atom through a single bond, i.e., $\mathbf{Y}=\mathrm{Br}$ and $\mathbf{Y}=\mathrm{NMe}_{2}$ in Figures $3 \mathrm{a}$ and $3 \mathrm{~b}$. We first focus on the di-protonated systems, analogous to the parent $\mathrm{AH}_{2}^{2+}$, that possess only one tautomeric form, before discussing the impact of Y-substitution on other protonation states.

\subsubsection{Di-protonated ACPs}

The selected structural parameters (dihedral angles $\phi$ and CN/CC bond lengths of the substituted peripheral subsystem, see Figure 4), NICS(0), and HOMA values obtained for single-bonded substituents are listed in Table 3 . As can be seen both aro- maticity indices predict a strongly aromatic macrocycle and nonaromatic/anti-aromatic six-member cycles i.e., both models provide the same qualitative pictures. Looking first at the impact of the addition of four peripheral ethyl chains, i.e., comparing the parent ACP and the unsubstituted Y-ACPs (with $\mathrm{Y}=\mathrm{H}$ ), one observes quasi-identical structures and similar central NICS(0) and HOMA values, which is consistent with Ref. 13 that reported mild influence of $\mathrm{N}$-alkyl substitution. One notices that B and D (A and $\mathrm{C}$ ) phenyl-like rings present a larger (smaller) anti-aromatic character when adding ethyl chains. This is again consistent with results of Ref. 13 and this trend can be related to the lengths of the (single) CC bonds separating the central cycle and the peripheral subunits. Indeed, while these single CC bond are $1.479 \AA$ in $\mathrm{AH}_{2}^{2+}$, they are sightly longer (shorter), 1.481 (1.477) $\AA$, in the $\mathrm{B} / \mathrm{D}(\mathrm{A} / \mathrm{C})$ rings in the $\mathrm{N}$-alkyl ACP.

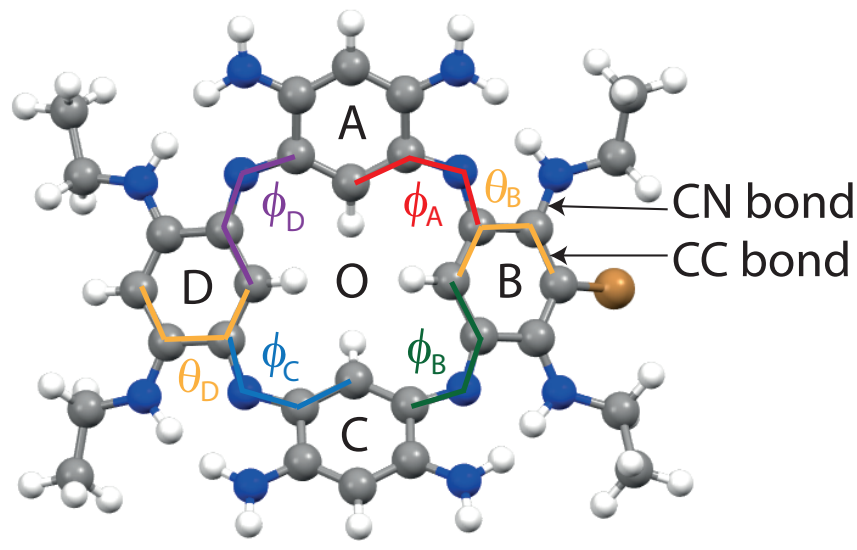

Fig. 4 Optimised structure of $\mathbf{Y}$-substituted ACP with $\mathbf{Y}_{1}=\mathrm{Br}$ and $\mathbf{Y}_{2}=\mathrm{H}$. The labels of the NICS centres, the dihedral angles, $\phi$ and $\theta$, and the CN and $\mathrm{CC}$ bonds discussed in the structural analysis are displayed.

All the optimised Y-substituted ACPs present a saddle-like structure and very small changes compared to the $\mathrm{Y}=\mathrm{H}$ macrocycle are found. This holds for both the distortions from the plane and the cyanine-like nature of the external subsystems, as indicated by their $\mathrm{CN}$ and $\mathrm{CC}$ bond length alternation in Table 3. As consequence, the aromaticity determined in these substituted systems is similar to the one of the non-substituted macrocycle, a statement holding for both NICS and HOMA indices, though the latter approach predicts stronger changes for the six-member rings bearing the $\mathbf{Y}$ group. Let us now turn towards the evolution of the optical properties of the ACPs upon Y-substitution with bromine atoms or dimethylamino groups. Details of the computed absorption wavelengths obtained with the two functionals are given in Section S3 in the ESI. The theoretical spectra obtained with both PBE0 and CAM-B3LYP exchange-correlation functionals are displayed in Figure 5. One first notices that these two XCFs essentially deliver the same conclusion: substituting the central carbon atom by one or two $\mathrm{Br} / \mathrm{NMe}_{2}$ atom(s)/group(s) has a trifling impact on the optical properties of the ACP. Irrespective of the selected XCF, the NIR band is redshifted by 0.01 to $0.04 \mathrm{eV}$ only when going from $\mathrm{Y}=\mathrm{H}$ to $\mathrm{Y}=\mathrm{Br}$ or $\mathrm{NMe}_{2}$. The nature of the PBE0 and CAM-B3LYP transitions responsible for the two first absorption bands together with the representation of the 
Table 3 Point group (PG) symmetry, selected geometrical parameters, NICS(0) (in ppm) and HOMA values for Y-substituted di-protonated ACPs. The labels and various parameters ( $\phi$ an $\theta$ angles in degrees and bond lengths in $\AA$ ) are displayed in Figure 4 .

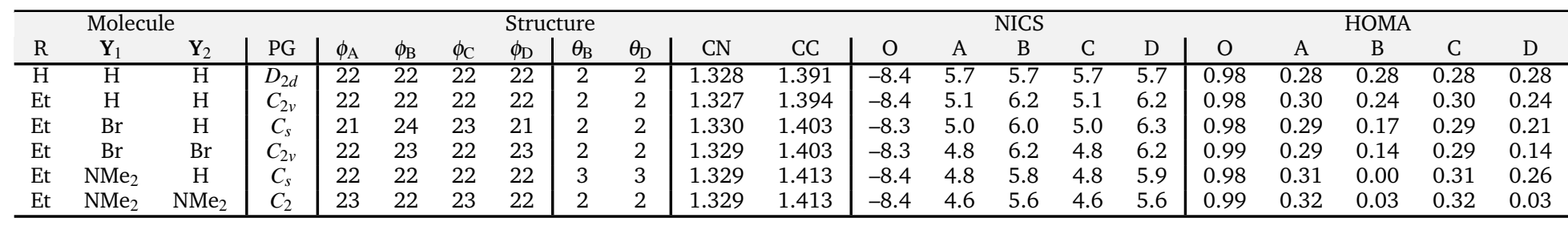
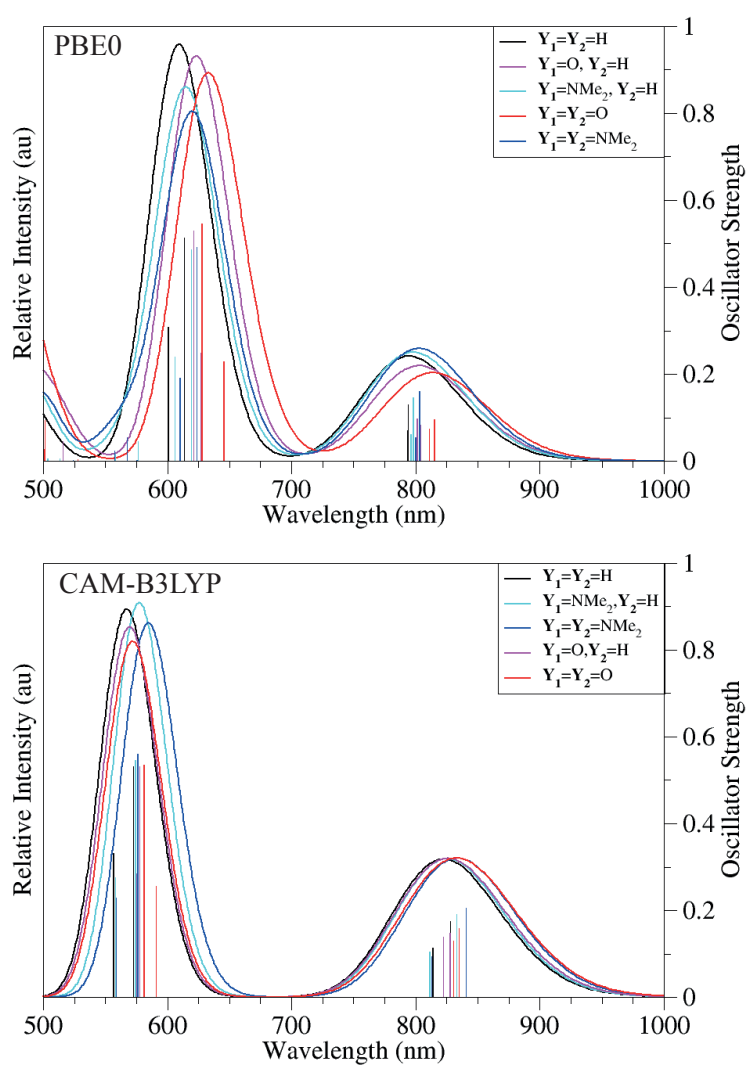

Fig. 5 Theoretical spectra of the non-substituted (black), mono-/disubstituted with $\mathrm{Y}=\mathrm{Br}$ (violet/red), and $\mathrm{Y}=\mathrm{NMe}_{2}$ (cyan/blue) di-protonated ACPs using PBE0 (top) and CAM-B3LYP (bottom) functionals. The vertical transitions (sticks) have been convoluted with a Gaussian presenting a FWHM of $1500 \mathrm{~cm}^{-1}$.

frontier molecular orbitals are given in the ESI (Tables S4-S5 and Figures S7-S8). Consistently with the absence of clear shifts in Figure 5, one sees that the topologies of the frontier orbitals are not or only very slightly involving the central carbon atoms and its Y group. Comparing with Y-substituted polymethine dyes, ${ }^{18}$ similar limited changes in the absorption spectrum were observed for the bromo-derivative. In contrast, the addition of a dialkylamino group on polymethine yields a large change in the absorption profile, whereas this effect is totally absent in the ACPs. As one can see in Figure S7, this can be explained by the unfavourable orientation of the $\mathrm{NMe}_{2}$ group: the steric hindrance of the ethyl chains induces a twisting of the donor group which greatly diminishes its efficiency. This hypothesis of a steric (and not electronic) origin was confirmed by using two $\mathrm{NH}_{2}$ groups in lieu of the $\mathrm{NMe}_{2}$ moieties: in the former case, there is no significant twisting of the amino group. As a consequence, the impact on the optical properties is more significant when adding a $\mathrm{NH}_{2}$ than a $\mathrm{NMe}_{2}$ group (see bottom of Table S4 in the ESI).

\subsubsection{Other protonation states}

Although single bonded substituents do not impact directly the absorption spectra, it remains interesting to study their indirect impact on the relative stabilities and spectra of the different protonated/deprotonated forms of the ACPs, that might exist under various tautomeric forms. Indeed, as already demonstrated in Ref. 12, substitution can play a role on the tautomeric equilibrium and the different tautomers of the ACP do not systematically absorb at similar wavelengths. Consistently with the experimentally accessible forms for the unsubstituted ACP, we focus on the effect of the $\mathrm{Y}$-substitution (with $\mathrm{Y}=\mathrm{Br}$ and $\mathrm{Y}=\mathrm{NMe}_{2}$ ) when protonating the bridge (leading to $\mathrm{AH}_{3}^{3+}$ derivatives) or deprotonating once ( $\mathrm{AH}^{+}$derivatives) or twice (A derivatives) the peripheral amino groups. The considered structures are displayed in Figure 6 for both asymmetric and symmetric substitution patterns.

One should first analyse the relative stabilities of the possible tautomers of the Y-substituted ACPs that are listed in Table S6 in the ESI. For asymmetrically Y-substituted $\mathrm{AH}_{3}^{3+}$ system, two non-equivalent structures, denoted $\mathbf{a}$ and $\mathbf{b}$, have been modelled and it turns out that, irrespective of the electroactive group, both tautomers present comparable energies, protonating the nitrogen bridge vicinal to the substituted ring being slightly less favourable than protonating the a site (see Figure 6). For the mono-protonated unsubstituted compound $\mathrm{Y}=\mathrm{H}$, tautomer $\mathbf{1}$ is more stable than 2 by ca. $4 \mathrm{kcal} / \mathrm{mol}$. This can be related to the presence of an alkyl chain at position 2 . Indeed, the inductive donating effect of the peripheral chains yields a relative destabilisation of the imino function compared to the amino group, consistently with Ref. 12 . With both $\mathrm{Y}=\mathrm{Br}$ and $\mathrm{Y}=\mathrm{NMe}_{2}$, similar outcomes are obtained, that is, $\mathbf{1}$ (and $\mathbf{5}$ for the asymmetrically substituted compounds) are favoured compared to $\mathbf{2}$ (and $\mathbf{6}$ for asymmetric substitution). One also notes that compared to $\mathrm{Y}=\mathrm{H}$, the free energy of $\mathbf{2}$ is only $1.0 \mathrm{kcal} / \mathrm{mol}$ higher than that of the most stable tautomer for $\mathbf{Y}_{1}=\mathrm{Br}$, probably due to the inductive accepting effect of the bromine atom that partially counterbalances the inductive donating effect of the peripheral alkyl chains. For the neutral forms, let us first assess the influence of the addition of alkyl chains, i.e., compare the $\mathrm{Y}=\mathrm{H}$ results of Table $\mathrm{S} 6$ to the ones obtained for ACP A in Table S1. The 1-4 and 1-5 tautomers are clearly favoured by the presence of alkyl chains at position $\mathbf{2}$, 3,6 , and 7 . One also notes that the most energetic tautomers 


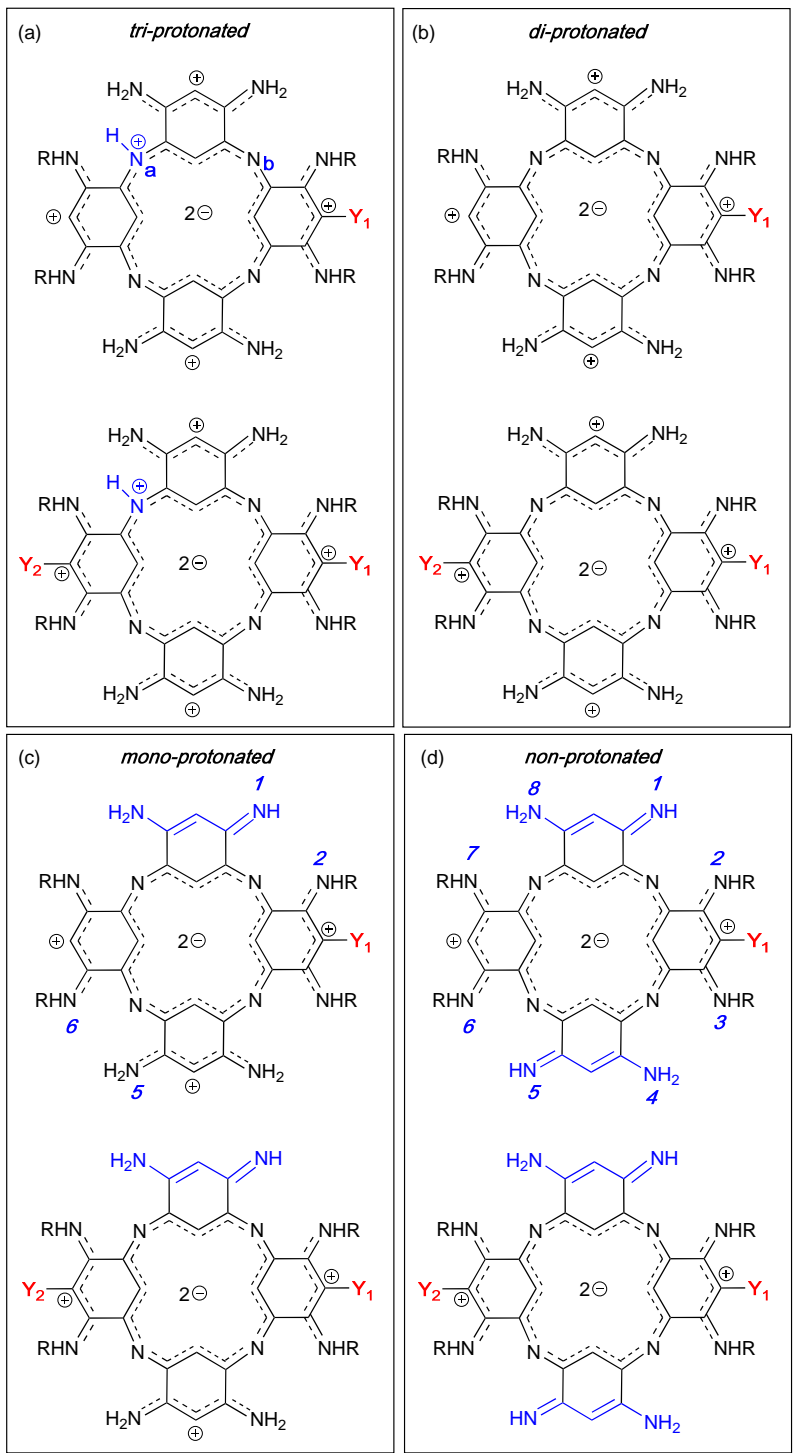

Fig. 6 Representation of the asymmetrically (top) and symmetrically (bottom) substituted structures of the (a) tri-, (b) di-, (c) mono-, and (d) non-protonated single-bond Y-substituted ACPs. The changes upon protonation/deprotonation of the di-protonated ACP are highlighted in blue. The position of the protonated bridging nitrogen atom ( $\mathbf{a}$ or $\mathbf{b})$ and of the imino group(s) (from $\mathbf{1}$ to $\mathbf{8}$ ) are labeled on the structures at the top.

(with relative free energies larger than $15 \mathrm{kcal} / \mathrm{mol}$ ) are, as expected, 1-8 and 2-3 in which the two imino functions are borne by the same phenyl-like ring. In the symmetrically Y-substituted species, similar outcomes are found, for the amino substituent: the 1-4 and 1-5 tautomers are even more stabilised compared to the other forms, and these tautomers are likely strongly dominant in solution. In contrast, for brominated compounds, more tautomers with relative free energies inside the $1.5 \mathrm{kcal} / \mathrm{mol}$ window are found, i.e., 1-2, 1-3, 1-4, 1-5, 1-6, and 1-7 (see Table S6). For the asymmetric substitution pattern, similar conclusions are reached, i.e., the central amino group does not impact the tautomeric blend whereas more tautomers are predicted to co-exist in solution when adding a bromine atom at the $\mathrm{Y}_{1}$ position.

The aromaticity and optical properties of the tautomers pos- sessing a relative free energy within $3 \mathrm{kcal} / \mathrm{mol}$ have been determined for the mono- and tri-protonated macrocycles that present a tractable number of tautomers and for which the parent ACPs was only presenting one tautomeric form. The results are listed in Table S7 in the ESI. The NICS(0) values at the centre of the macrocycles are almost unaffected by substitution. In addition, one notices that, compared to their di-protonated counterparts, the tri-protonated species present similar NICS(0) values, whereas the global aromaticity of the mono-protonated compounds is slightly smaller. This is completely consistent with the NICS analysis of the parent A derivatives (see Table S1 of the ESI). For the optical properties, we discuss the PBE0 results only, as the selected XCF has a very small influence for the diprotonated system (vide supra) As illustrated in Figure 7, substitution of the mono- and tri-protonated forms can induce slightly larger effects on the optical properties than in the di-protonated case. For the tri-protonated species, the auxochromic shifts are larger for the second absorption band (up to $-0.07 \mathrm{eV}$ ) than for the NIR band (up to $-0.03 \mathrm{eV}$ ). For the mono-protonated compound, while almost no changes are obtained between the $\mathrm{Y}=\mathrm{H}$ and the $\mathrm{Y}=\mathrm{NMe}_{2}$ ACPs, the substitution with bromine yields slightly more pronounced bathochromic effect. In particular, the effect becomes significant for the symmetrically substituted compounds for which the two absorption bands are respectively redshifted by -0.07 and $-0.08 \mathrm{eV}$. Finally although the presence of several tautomers can, in principle, induce broader absorption bands, this strategy is not very successful here because all tautomers essentially absorb at the same energies.

\subsection{Double bonded Y substituents}

We now turn to the impact of $\mathbf{Y}$ substituents linked to the ACPs through double bonds. Alike in the previous Section, we first focus on the analogues of the parent $\mathrm{AH}_{2}^{2+}$ (displayed in Figures 3c and $3 \mathrm{~d}$ ) before turning to ACPs with different protonation states.

\subsubsection{Di-protonated ACPs}

The selected geometrical parameters, displayed in Figure 4 and the corresponding $\mathrm{NICS}(0)$ values obtained for the $\mathrm{Y}=\mathrm{O}$ and $\mathbf{Y}=$ NMe substituted ACPs are listed in Table 4. First, we underline that (i) in contrast to the $\mathrm{Br}$ and $\mathrm{NMe}_{2}$ derivatives, the structures investigated in this Section possess a formal total charge of +3 $(+4)$ for the asymmetrically (symmetrically) substituted species; (ii) the obtained point group of the symmetric keto-substituted ACP is not the expected $C_{2 v}$ but $C_{s}$ as the former returns an imaginary frequency. Although the $\mathbf{Y}$-substitution does not directly takes place on the central cycles, adding a keto or imino function yields a significant distortion of the global shape of the macrocycle, which contrast with the $\mathrm{Br}$ and $\mathrm{NMe}_{2}$ cases treated above. Indeed, the distortion angles range from 18 to $30^{\circ}$ and, within a given cycle, the largest deviation between the four dihedral angles $\phi_{\mathrm{A}}, \phi_{\mathrm{B}}, \phi_{\mathrm{C}}$, and $\phi_{\mathrm{D}}$ are obtained for the asymmetrically substituted species. Contrasting again with the single bonded Y-ACPs, adding keto $(\mathrm{Y}=\mathrm{O})$ or imino $(\mathrm{Y}=\mathrm{NMe})$ functions yields significant variations of the nature of the substituted peripheral cyanine subunits. Indeed, these functions induce the contraction (elongation) of the $\mathrm{CN}$ (CC) bonds, hinting that the system is no longer 
Table 4 Point group (PG) symmetry, selected geometrical parameters, NICS(0) (in ppm) and HOMA for Y-substituted di-protonated ACPs of Figure 3c and 3d. The label of the rings and the geometrical parameters, i.e., the dihedral angles ( $\phi$ and $\theta$ in degrees) and the $\mathrm{CN}$ and $\mathrm{CC}$ bond lengths (in $\AA$ ) in the substituted subsystem can be found in Figure 4.

\begin{tabular}{|c|c|c|c|c|c|c|c|c|c|c|c|c|c|c|c|c|c|c|c|c|c|}
\hline \multicolumn{3}{|c|}{ Molecule } & \multicolumn{9}{|c|}{ Structure } & \multicolumn{5}{|c|}{ NICS } & \multicolumn{5}{|c|}{ HOMA } \\
\hline $\mathrm{R}$ & $\mathbf{Y}_{1}$ & $\mathbf{Y}_{2}$ & PG & $\phi_{\mathrm{A}}$ & $\phi_{\mathrm{B}}$ & $\phi_{\mathrm{C}}$ & $\phi_{\mathrm{D}}$ & $\theta_{\mathrm{B}}$ & $\theta_{\mathrm{D}}$ & $\mathrm{CN}$ & CC & $\mathrm{O}$ & A & B & C & D & $\mathrm{O}$ & A & B & C & D \\
\hline$\overline{\mathrm{Et}}$ & $\overline{\mathrm{H}}$ & $\overline{\mathrm{H}}$ & $\overline{C_{2 v}}$ & 22 & 22 & 22 & 22 & 2 & 2 & 1.327 & 1.394 & -8.4 & 5.1 & 6.2 & 5.1 & 6.2 & 0.98 & $\overline{0.30}$ & 0.24 & 0.30 & 0.24 \\
\hline Et & $\mathrm{O}$ & $\mathrm{H}$ & $C_{s}$ & 19 & 30 & 25 & 20 & 4 & 2 & 1.305 & 1.496 & -7.7 & 6.1 & 5.1 & 6.1 & 7.4 & 0.97 & 0.18 & -0.25 & 0.18 & 0.10 \\
\hline Et & $\mathrm{O}$ & $\mathrm{O}$ & $C_{s}$ & 23 & 26 & 23 & 26 & 4 & 4 & 1.297 & 1.496 & -9.2 & 6.9 & 5.4 & 6.9 & 5.4 & 0.97 & 0.17 & -0.40 & 0.17 & -0.41 \\
\hline Et & $\mathrm{NMe}$ & $\mathrm{H}$ & $C_{1}$ & 19 & 30 & 25 & 21 & 19 & 2 & 1.299 & 1.483 & -7.9 & 5.8 & 4.4 & 6.0 & 7.5 & 0.97 & 0.21 & -0.16 & 0.21 & 0.12 \\
\hline Et & $\mathrm{NMe}$ & $\mathrm{NMe}$ & $C_{1}$ & 26 & 19 & 18 & 27 & 22 & 20 & 1.293 & 1.483 & -9.3 & 6.9 & 5.7 & 6.8 & 4.9 & 0.97 & 0.20 & -0.24 & 0.20 & -0.36 \\
\hline
\end{tabular}
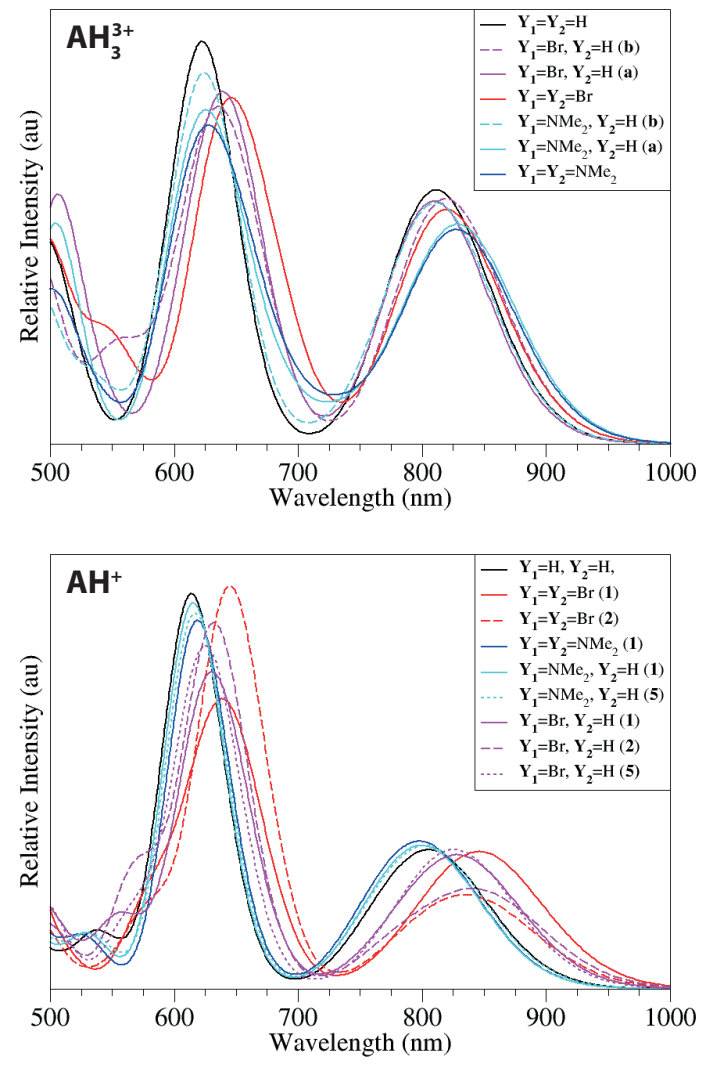

Fig. 7 Theoretical [PCM-PBE0/6-311+G(2d,p)] spectra of Y-substituted tri-protonated $\mathbf{A H}_{3}^{3+}$ (top) and mono-protonated $\mathbf{A H}^{+}$(bottom) ACPs displayed in Figure 6a and Figure 6c, repsectively. The label of the tautomer, in parenthesis, gives the position of the protonated bridging nitrogen atom (a or $\mathbf{b})$ for the tri-protonated ACPs or the position of the imino functions (from 1 to 8 ) for the non-protonated ACPs. The sticks have been convoluted with a Gaussian with a FWHM of $1500 \mathrm{~cm}^{-1}$ and have been omitted on the figures for the sake of clarity.

formed by bonds all presenting a 1.5 bond order but by an alternation of single CC (ca. $1.49 \AA$ ) and double CN bonds (ca. 1.30 $\AA$ ), consistent with the representation of Figure 3. Furthermore, it turns out that the phenyl-like ring bearing the $\mathrm{Y}$ group is distorted from planarity, and this effect is especially strong for the iminosubstituted compounds. Indeed, while the six-membered rings remain quasi-planar for $\mathrm{Y}=\mathrm{H}, \mathrm{Br}$, and $\mathrm{NMe}_{2}$ derivatives $\left(\theta=2^{\circ}\right)$ as well as for $\mathbf{Y}=\mathrm{O}$ compounds $\left(\theta=4^{\circ}\right)$, they are largely deformed in $\mathrm{Y}=\mathrm{NMe}$ derivatives, the dihedral angle $\theta$ reaching ca. $20^{\circ}$.

We now compare the macrocyclic aromaticity in these $\mathbf{Y}$ substituted ACPs to their non-substituted $(\mathrm{Y}=\mathrm{H})$ counterpart. While the global aromaticity remains unchanged when adding single bonded substituents $\left(\mathrm{Y}=\mathrm{Br}\right.$ and $\left.\mathrm{NMe}_{2}\right)$, the NICS(0) values at the centre of the macrocycles interestingly differ when adding substituents attached to the central carbon through a double bond. This change is not detected with the HOMA approach that systematically provides a value close to 1 , that is to "perfect" aromaticity. One observes that: (i) the global aromaticity is slightly smaller [NICS(0) of ca. $-8 \mathrm{ppm}$ ] for asymmetric systems than for symmetrically Y-substituted ACPs [NICS $(0)$ of ca. $-9 \mathrm{ppm}]$, the latter therefore being more aromatic than the ACP parent; (ii) the substituted rings present a smaller antiaromatic character than the other six-member rings; and (iii) for asymmetrically-substituted compounds, the largest anti-aromatic character is obtained for the D ring, the furthest away from substitution. For these latter rings, the HOMA values are also close to zero.

The theoretical spectra obtained using both PBEO and CAMB3LYP functionals are displayed in Figure 8, the corresponding raw values and involved molecular orbitals being given in Section S4.1 of the ESI. The two XCFs deliver qualitatively different results. In particular for compounds with $\mathrm{Y}=\mathrm{O}$, limited variations are observed on the PBE0 spectra for both absorption bands whereas CAM-B3LYP predicts significant changes of the NIR band upon substitution. For the doubly-substituted $\mathrm{Y}=\mathrm{O}$ derivatives, although both PBE0 and CAM-B3LYP deliver a similar nature of the first dipole-allowed transition (in terms of both contribution of molecular orbitals to this transition and their topologies, see the ESI), PBE0 predicts the first band at $794 \mathrm{~nm}$ whereas it peaks at $899 \mathrm{~nm}$ for CAM-B3LYP. This is quite unusual that the functional encompassing the largest share of exact exchange yields the largest redshift, ${ }^{39}$ especially for a state that apparently presents a partial charge-transfer character (see the MOs in Figures S9 and S10). ${ }^{40}$ In order to discriminate which of the two XCF is providing the most accurate description of the optical spectrum, CC2 calculations were performed for the four derivatives. The results are reported in Table S10 in the ESI and it is clear that PBEO delivers transition energies that are very close to CC2 ones, with deviations in the 0.01-0.09 eV window and a MAD as small as $0.06 \mathrm{eV}$. Much larger errors, up to $0.21 \mathrm{eV}$ with a MAD of 0.14 $\mathrm{eV}$ are obtained with CAM-B3LYP. Consequently, the PBE0 results are more trustworthy and they indicate that rather limited variations upon substitution are expected. More in details, one notices in Figure 8 that: (i) the spectrum of asymmetric species remains quasi-unchanged whereas larger variations are obtained for symmetrically-substituted ACPs; (ii) a small hyperchromic effect is observed for the $\mathbf{Y}_{1}=\mathbf{Y}_{2}$ species; and (iii) the impact of the 
Table 5 Dihedral distortion ( $\phi$ in degrees) and NICS(0) values (in ppm) for $\mathbf{Y}$-substituted ACPs in several protonation states with $\mathbf{Y}=\mathrm{O}$ and $\mathbf{Y}=\mathrm{NMe}$. Only low-energy tautomers are considered (see Table S11). The values in bold corresponds to a phenyl ring bearing one or two imino functions. The label of the tautomers, of the rings and of the $\phi$ angles are displayed in Figure 4.

\begin{tabular}{lccc|cccc|ccccc}
\hline State & $\mathrm{Y}_{1}$ & $\mathbf{Y}_{2}$ & Tautomer & $\phi_{\mathrm{A}}$ & $\phi_{\mathrm{B}}$ & $\phi_{\mathrm{C}}$ & $\phi_{\mathrm{D}}$ & $\mathrm{O}$ & $\mathrm{A}$ & $\mathrm{B}$ & $\mathrm{C}$ & $\mathrm{D}$ \\
\hline Bridge-protonated & $\mathrm{H}$ & $\mathrm{H}$ & - & 24 & 25 & 26 & 26 & -8.3 & 2.4 & 6.5 & 5.8 & 4.1 \\
& $\mathrm{O}$ & $\mathrm{H}$ & $\mathbf{a}$ & 22 & 32 & 31 & 27 & -7.0 & 3.5 & 6.7 & 6.2 & 5.3 \\
& $\mathrm{O}$ & $\mathrm{H}$ & $\mathbf{b}$ & 22 & 41 & 37 & 35 & -5.0 & 4.3 & 6.4 & 5.4 & 6.3 \\
& $\mathrm{O}$ & $\mathrm{O}$ & - & 24 & 25 & 25 & 37 & -8.6 & 4.8 & 6.4 & 6.9 & 6.0 \\
& $\mathrm{NMe}$ & $\mathrm{H}$ & $\mathbf{a}$ & 21 & 33 & 31 & 26 & -7.2 & 3.2 & 4.6 & 5.8 & 5.2 \\
& $\mathrm{NMe}$ & $\mathrm{NMe}$ & - & 26 & 18 & 21 & 41 & -8.6 & 4.7 & 5.6 & 6.7 & 2.9 \\
\hline Singly-deprotonated & $\mathrm{H}$ & $\mathrm{H}$ & - & 22 & 19 & 24 & 26 & -6.4 & 7.3 & 5.6 & 1.9 & 4.3 \\
& $\mathrm{O}$ & $\mathrm{H}$ & $\mathbf{2}$ & 19 & 24 & 22 & 24 & -7.9 & 5.9 & $\mathbf{6 . 6}$ & 5.1 & 6.3 \\
& $\mathrm{O}$ & $\mathrm{O}$ & $\mathbf{2}$ & 25 & 23 & 19 & 30 & -7.4 & 6.6 & $\mathbf{7 . 9}$ & 6.1 & 5.8 \\
& $\mathrm{NMe}$ & $\mathrm{H}$ & $\mathbf{2}$ & 20 & 21 & 21 & 22 & -8.5 & 5.7 & $\mathbf{5 . 6}$ & 4.9 & 5.9 \\
& $\mathrm{NMe}$ & $\mathrm{NMe}$ & $\mathbf{2}$ & 30 & 19 & 18 & 31 & -7.6 & 6.2 & $\mathbf{6 . 6}$ & 5.6 & 4.2 \\
\hline Doubly-deprotonated & $\mathrm{O}$ & $\mathrm{H}$ & $\mathbf{2 - 3}$ & 23 & 20 & 21 & 23 & -7.9 & 4.8 & $\mathbf{9 . 9}$ & 4.8 & 4.2 \\
& $\mathrm{O}$ & $\mathrm{O}$ & $\mathbf{2 - 6}$ & 20 & 23 & 20 & 23 & -7.7 & 5.9 & $\mathbf{6 . 7}$ & 5.9 & $\mathbf{6 . 7}$ \\
& $\mathrm{O}$ & $\mathrm{O}$ & $\mathbf{2 - 7}$ & 22 & 24 & 22 & 25 & -7.6 & 6.3 & $\mathbf{6 . 6}$ & 5.1 & $\mathbf{6 . 6}$ \\
& $\mathrm{NMe}$ & $\mathrm{H}$ & $\mathbf{2 - 3}$ & 22 & 16 & 20 & 24 & -7.5 & 4.7 & $\mathbf{6 . 9}$ & 5.0 & 3.8 \\
& $\mathrm{NMe}$ & $\mathrm{NMe}$ & $\mathbf{2 - 6}$ & 19 & 23 & 24 & 19 & -8.8 & 5.6 & $\mathbf{6 . 7}$ & 5.5 & $\mathbf{5 . 6}$ \\
\hline
\end{tabular}
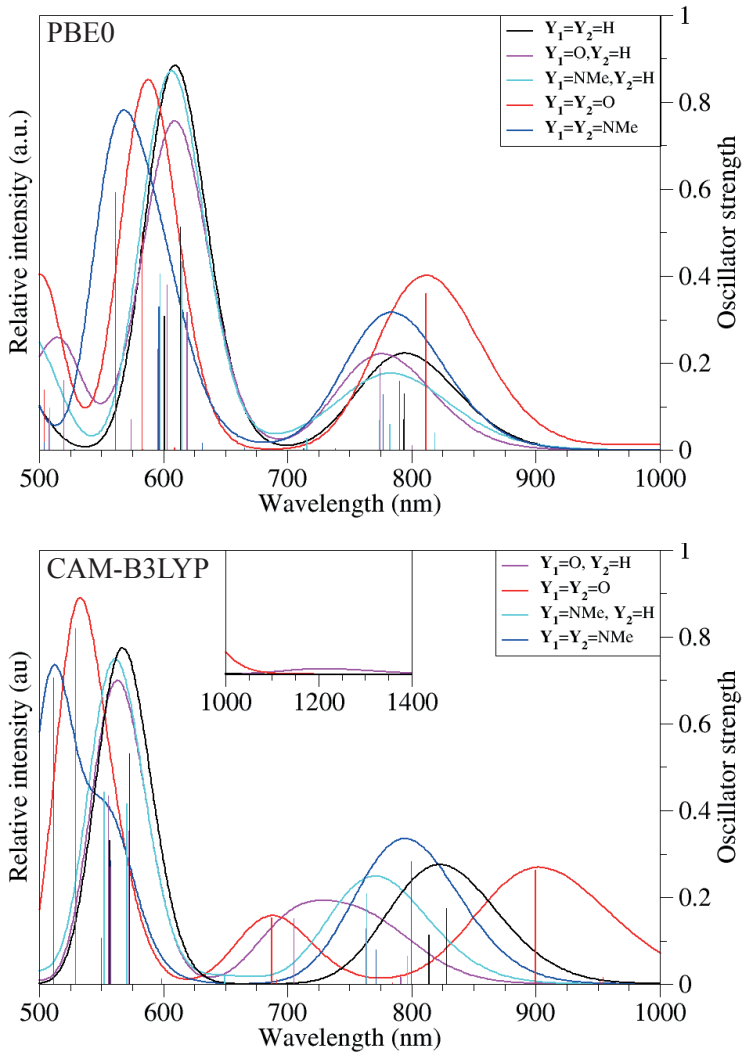

Fig. 8 Theoretical spectra of the non-substituted (black), the mono-/disubstituted with $\mathrm{Y}=\mathrm{O}$ (violet/red), and $\mathrm{Y}=\mathrm{NMe}$ (cyan/blue) azacalixphyrin using the PBE0 (top) and CAM-B3LYP (bottom) functionals. An inset is given for the long wavelength transition determined with CAM-B3LYP. The TD-DFT vertical transitions (sticks) have been convoluted using a Gaussian function with a FWHM of $1500 \mathrm{~cm}^{-1}$.

substituent is also significant for the band at ca. $600 \mathrm{~nm}$. The density difference plots corresponding to the lowest dipole-allowed transition is displayed in Figure 9 for the keto derivatives. As can be seen, a delocalized transition with reorganisation of the the density around the macrocycle are found, as in the parent ACP (see Figure S6), in line with the small changes of wavelengths computed with TD-DFT.

At this stage, the Y-substitution pattern does not seem to stand as an efficient strategy to tune the absorption properties of the ACPs. Nevertheless, as the protonation state of this envisioned molecules can be tuned and as the both keto- or imino- substitutions can, in principle, induce significant variations of the tautomeric blend, we investigate several protonation states of these $\mathrm{Y}=\mathrm{O}$ and $\mathrm{Y}=\mathrm{NMe}$ ACP derivatives in the following Section.
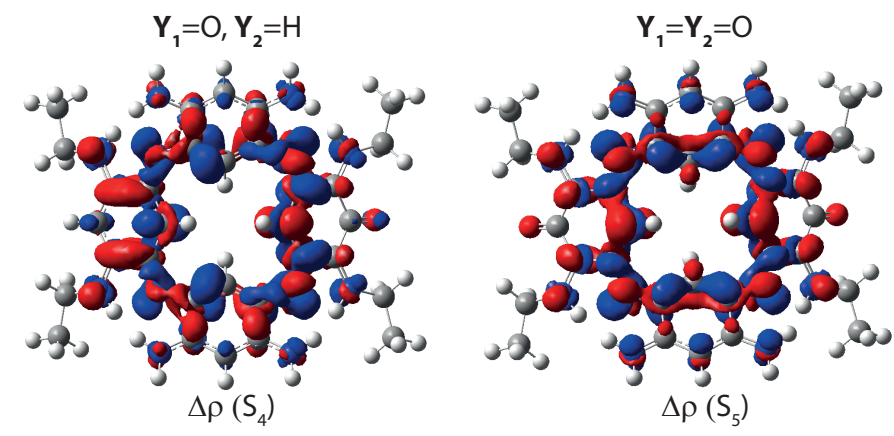

Fig. 9 Electronic density difference (isovalue $=0.0004$ a.u.) corresponding to the lowest significantly dipole-allowed state of the $Y$-substituted ACPs shown in Figure $3 a$ and $b$, with $Y_{1}=O$ and $Y_{2}=H$ (left) and $\mathbf{Y}_{1}=\mathbf{Y}_{2}=\mathrm{O}$ (right) obtained at the PCM-PBE0/6-311+G(2d,p) level of theory. Red/blue regions indicate gain/loss of electronic density upon photon absorption.

\subsubsection{Other forms}

By analogy with the previous cases, three different protonation states have been modelled: (i) the analogue of the tri-protonated $\mathrm{AH}_{3}^{3+}$, in which all the external functions are amino groups and one nitrogen atom of the bridge are protonated; (ii) the analogue of the mono-protonated $\mathrm{AH}^{+}$, that presents $7 / 1$ exter- 
nal amino/imino functions; and (iii) the analogue of the nonprotonated $\mathrm{A}$, that presents $6 / 2$ external amino/imino functions. These structures are sketched in Figure 10 and follow the same numbering as the one applied in Figure 6. As mentioned for the di-protonated substituted ACPs with $\mathrm{Y}=\mathrm{O}$ and $\mathrm{Y}=\mathrm{NMe}$, the total charge of these systems varies compared to their non-substituted parent and we denote the species as bridge-protonated, singlydeprotonated, and doubly-deprotonated ACP derivatives, in the following.

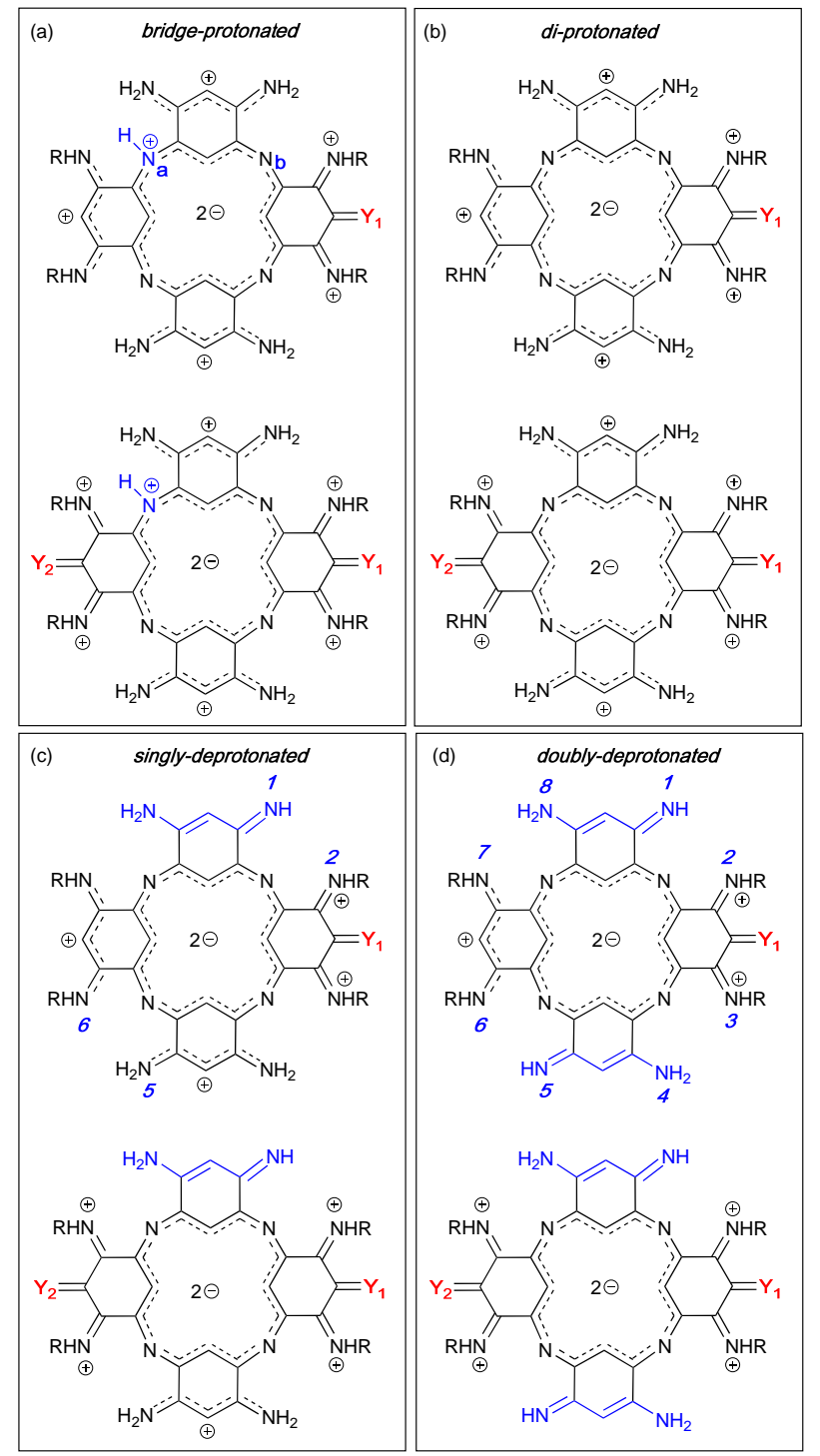

Fig. 10 Representation of the asymmetrically (top) and symmetrically (bottom) structures of the (a) bridge-protonated, (b) di-protonated, (c) singly-deprotonated, and (d) doubly-deprotonated Y-substituted ACPs. See caption of Figure 6 for details.

As several possible tautomers exist for each protonation state, we first analyse the relative free energies of all possible tautomers (Table S11) before studying the geometry, aromaticity, and absorption properties of the most stable ones. For the bridgeprotonated species, in line with the findings reached for the bromine and amino substitutions, the protonation of a bridging
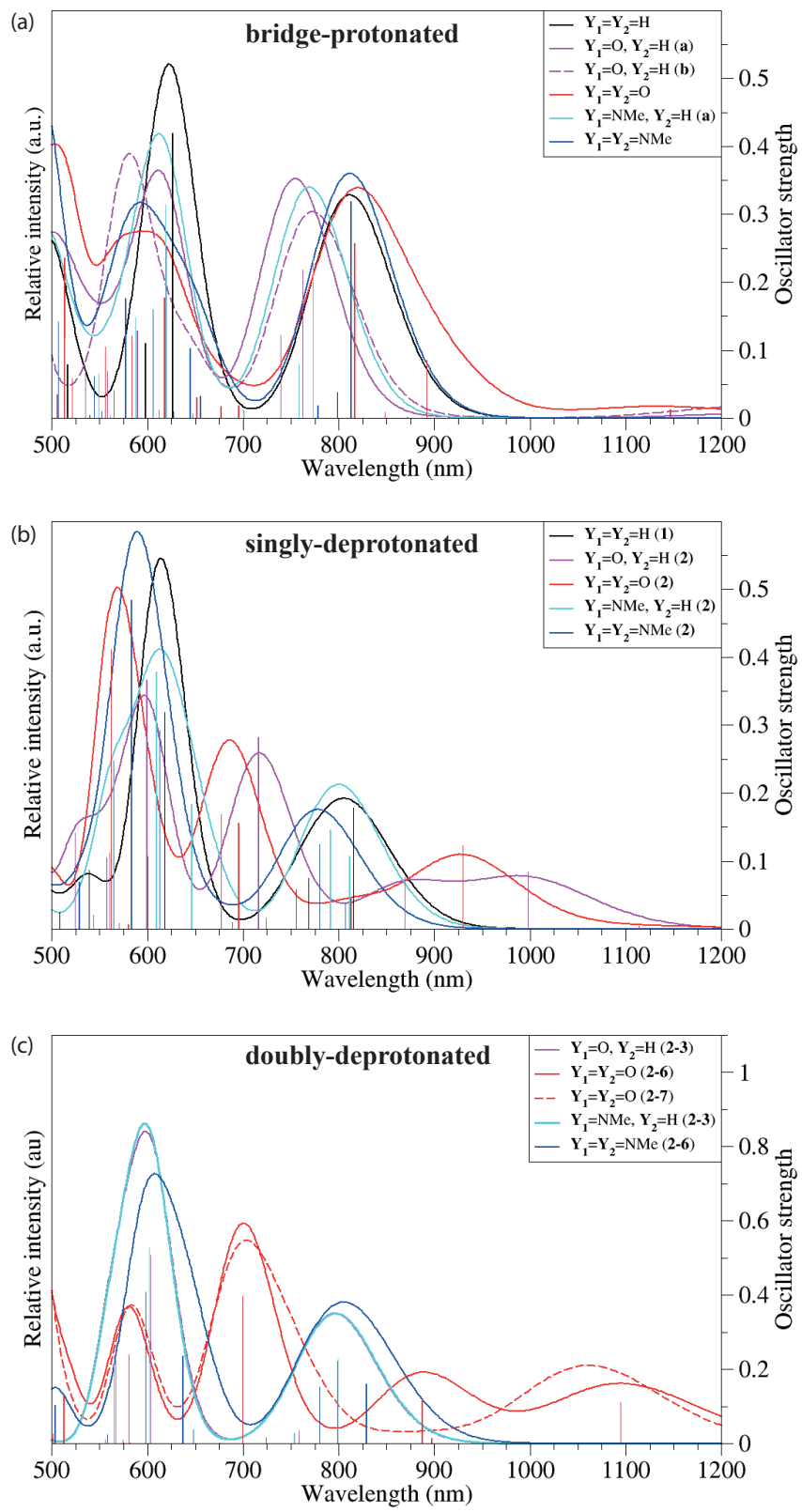

Fig. 11 Theoretical [PCM-PBE0/6-311+G(2d,p)] spectra of the $\mathbf{Y}=\mathrm{H}$ (black), mono-/di-substituted with $\mathbf{Y}=\mathrm{O}$ (violet/red) and $\mathbf{Y}=\mathrm{NMe}_{2}$ (cyan/blue) ACPs in several protonation states: (a) bridge-protonated, (b) singly-deprotonated, and (c) doubly-deprotonated states. The vertical TD-DFT energies (sticks) have been convoluted with a Gaussian presenting a FWHM of $1500 \mathrm{~cm}^{-1}$.

nitrogen atom at the a position is favoured compared to the $\mathbf{b}$ site. In other words, protonation takes place far from the substituted ring. One also notes that the $\mathbf{b}$ tautomer is more destabilised for the imino-substituted ACP than for the keto-substituted ACP, an outcome that we attribute to the stronger electro-accepting character of the oxygen atom compared to the NMe group. For the singly-deprotonated species, only one tautomer, in which the imino function is located at position $\mathbf{2}$, is found to be stable, all the other structures present energies ca. $20 \mathrm{kcal} / \mathrm{mol}$ above that structure. This outcome, in sharp contrasts with the findings obtained with $\mathrm{Y}=\mathrm{H}, \mathrm{Br}$, and $\mathrm{NMe}_{2}$, can be understood: the 
external moiety encompassing the Y-substituted subsystem bears two formal positive charges localised on each iminium groups, so that their deprotonation is therefore much favoured, compared to the cases in which the positive charge is delocalised over a cyanine-like subsystem. A logical consequence of this observation is that, only one (three) form(s) possibly co-exist for the doubly-deprotonated asymmetrically- (symmetrically-) substituted species, that is, the 2-3 (2-3, 2-6, and 2-7) tautomer(s), in which the NHR groups of the Y-substituted moiety (moieties) are deprotonated so to remove the positive charge localised on these groups. In the following, only structures that present free energies within the $3 \mathrm{kcal} / \mathrm{mol}$ window are considered.

The dihedral distortion and NICS(0) values are reported in Table 5 . For the bridge-protonated compounds, large structural distortions are obtained with $\phi$ angles ranging from 18 to $41^{\circ}$, compared to both their unsubstituted $(\mathrm{Y}=\mathrm{H})$ and their di-protonated counterparts (see Table 4). While similar aromatic characters as previously are obtained for the symmetric ACPs, with NICS(0) of ca. $-8.5 \mathrm{ppm}$, the NICS $(0)$ values at the centre of the macrocycle of asymmetrically substituted compounds are increased by ca. $1.5 / 2.5 \mathrm{ppm}$ for the $\mathbf{a} / \mathbf{b}$ tautomers, and attain ca. -5.0 ppm. For the deprotonated derivatives, smaller distortions of the central cycle are observed, with $\phi$ between 18 and $31^{\circ}$ for the singly-deprotonated compounds and even more planar macrocycles upon double deprotonation, with $\phi$ ranging from 16 to $24^{\circ}$. The macrocycles with deprotonated amino function(s) (that is showing imino group(s)) are therefore strongly aromatic with NICS(0) value at their centre between -7.4 and $-8.8 \mathrm{ppm}$.

Let us now turn to the optical properties of the doubly bonded protonated/deprotonated species focusing on the NIR absorption band. On the spectra of the bridge-protonated species (Figure 11a), one observes that the NIR band of the symmetricallysubstituted ACPs peaks at the same wavelength as for the nonprotonated $\mathrm{Y}=\mathrm{H} \mathrm{ACP}$, and that they are redshifted compared to their asymmetrically substituted counterparts. The nature of the dipole-allowed electronic transitions and of the molecular orbitals (topologies and energies) involved in these transitions are respectively reported in Table S12 and Figure S12 in the ESI whereas Figure 12 provides density difference plots for the lowest transitions. For both keto- and imino-substitutions, adding two $\mathbf{Y}$ groups yields a stabilisation of all the frontier orbitals, this effect being more pronounced for the LUMO than for the occupied orbitals which therefore explains the redshifts. In addition, one observes that the di-keto compound displays a broader NIR absorption band. This is due to CT transitions that are absent in the other compounds. Indeed, the CT character of the first dipoleallowed transitions is clearly observed on the density difference plot of Figure 12, with the keto-bearing subunits acting as strong acceptors. As we are well aware that PBE0 may sometimes lead too small transition energies when a significant CT takes place, we have performed gas phase CC2 calculations for this latter compound. It turns out that the lowest state presenting an oscillator strength larger than 0.1 appears at nearly the same energy as with TD-PBE0 (difference of $6 \mathrm{~nm}$ or $0.01 \mathrm{eV}$ ).

Deprotonation can induce more significant spectral changes for the keto-derivatives. Indeed, for the mono-deprotonated ACPs
(Figure 11b), both symmetric and asymmetric keto-derivatives present redshifted spectra at ca. $1000 \mathrm{~nm}$ compared to iminosubstituted ACPs (ca. $800 \mathrm{~nm}$ ). The nature of the electronic transition and molecular orbitals for the deprotonated species are detailed in the ESI, whereas the electronic density difference plots of the first dipole-allowed transition in Figure 13 show that these bands clearly involve strong density reorganization with a chargetransfer character, thus explaining the observed bathochromic shifts. Interestingly, irrespective of the number of keto functions added, these excitations arise from a CT from the overall macrocycle to the keto subunit bearing the deprotonated amino function. For $\mathbf{Y}=\mathrm{NMe}$ compounds, no significant changes of the spectra are observed but the CT character of the first dipole-allowed excitation is less marked (Figure 13). This can possibly be related to the negative impact of the imino-substituted species on the planarity of the ACPs, that could partially counterbalance the electronic effect, and hence limit the CT. For the doubly-deprotonated species (Figure 11c), theory predicts almost no change of band position for the dominating 2-3 tautomer with $\mathbf{Y}_{1}=\mathrm{O}$ and $\mathbf{Y}_{2}=\mathrm{H}$ (compare Figures 8 and 11c). This can be understood by the topology of the excited-state displayed on the left of Figure 14, and also by comparing the MO shapes and energies of Figures S9 and S14 in the ESI. Indeed, in both the original (Figure S9) and the doubly-deprotonated (Figure S14) forms, the NIR band is related to a HOMO to LUMO+ 1 transition and these MOs have similar shapes, the energies of both the occupied and virtual orbitals being significantly downshifted (by a rather similar energy) in the doubly-deprotonated ACP. More interestingly theory foresee large bathochromic effects for the stable 2-6 and 2-7 tautomers of the di-keto $\left(\mathrm{Y}_{1}=\mathrm{Y}_{2}=\mathrm{O}\right)$ compound with a maximal absorption wavelength at ca. $1100 \mathrm{~nm}$. This trend can be explained as the nature of the virtual orbital mainly involved in the transition is significantly modified by double deprotonation: while in the original system the key LUMO +2 is highly symmetric and located at $-4.61 \mathrm{eV}$ (Figure S9), in the doubly-deprotonated ACP the LUMO is now centered in the vicinity of the keto groups and presents a much lower energy: -4.25 and $-4.20 \mathrm{eV}$ for the 2-6 and 2-7 tautomers, respectively (Figure S14). It is therefore clear that the two keto-subsystems are now both involved in the CT (see Figure 14) occurring from the overall macrocycle towards the two Y-substituted moieties, each bearing a deprotonated amino function. We have (again) checked the results obtained for the 2-6 tautomer with CC2 and found an excellent agreement, with the lowest transition within $8 \mathrm{~nm}$ of each other in gas phase.

\section{Conclusions}

In this work, we screened a series of Y-substituted azacalixphyrins, focusing on the impact of this substitution pattern on the structure, aromaticity, and absorption of the ACP. For groups binding at $\mathrm{Y}$ through single bonds, no significant changes on the ACP properties are predicted irrespective of the nature of the substituents ( $\mathrm{Br}$ and $\mathrm{NMe}_{2}$ ), of their number (one or two), and of the protonation state of the ACPs. This can be rationalized by the fact that bromine is a mild auxochromic group whereas the steric hindrance with the ethyl chains of the ACP induces a significant distortion of the $\mathrm{NMe}_{2}$ group, making it almost orthogonal to the 

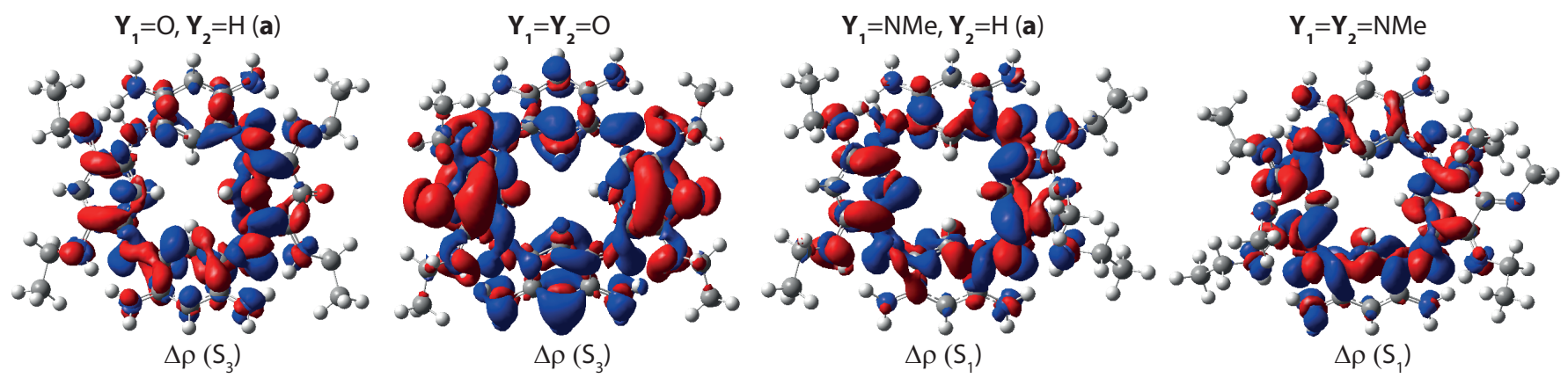

Fig. 12 Electronic density difference corresponding to the lowest significantly dipole-allowed state (see Table S12) of the bridge-protonated $\mathbf{Y}$ substituted ACPs with (from left to right) $\mathbf{Y}_{1}=\mathrm{O}$ and $\mathbf{Y}_{2}=\mathrm{H}, \mathbf{Y}_{1}=\mathbf{Y}_{2}=\mathrm{O}, \mathbf{Y}_{1}=\mathrm{NMe}$ and $\mathbf{Y}_{2}=\mathrm{H}$, and $\mathbf{Y}_{1}=\mathbf{Y}_{2}=\mathrm{NMe}$. See caption of Figure 9 for more details.
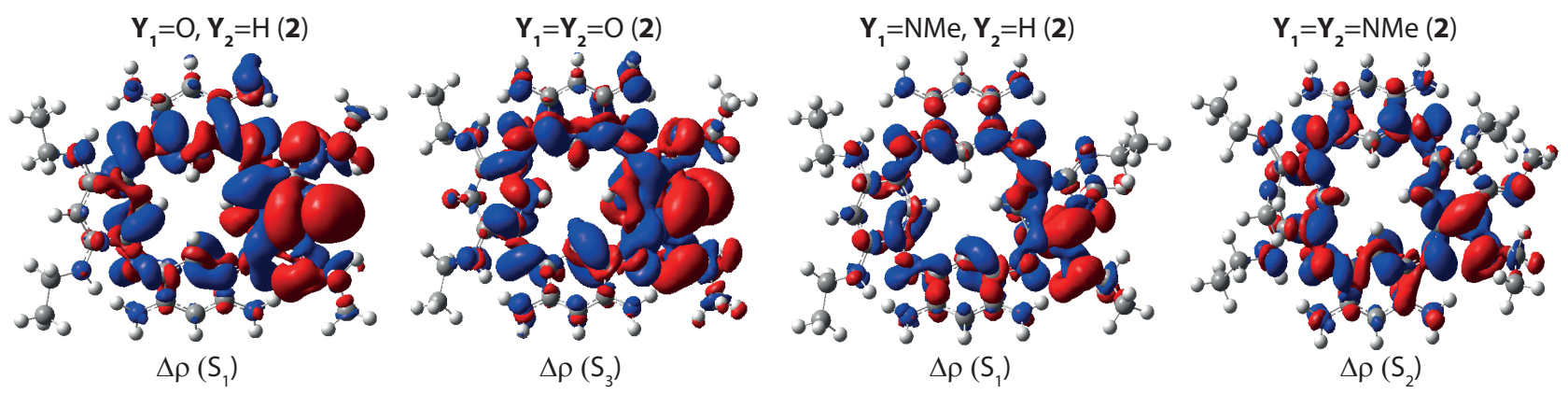

Fig. 13 Electronic density difference corresponding to the first absorption band of the singly-deprotonated $\mathbf{Y}$-substituted ACPs with $\mathbf{Y}=\mathrm{O}$ and $\mathbf{Y}=\mathrm{NMe}$. See caption of Figure 9 for more details.

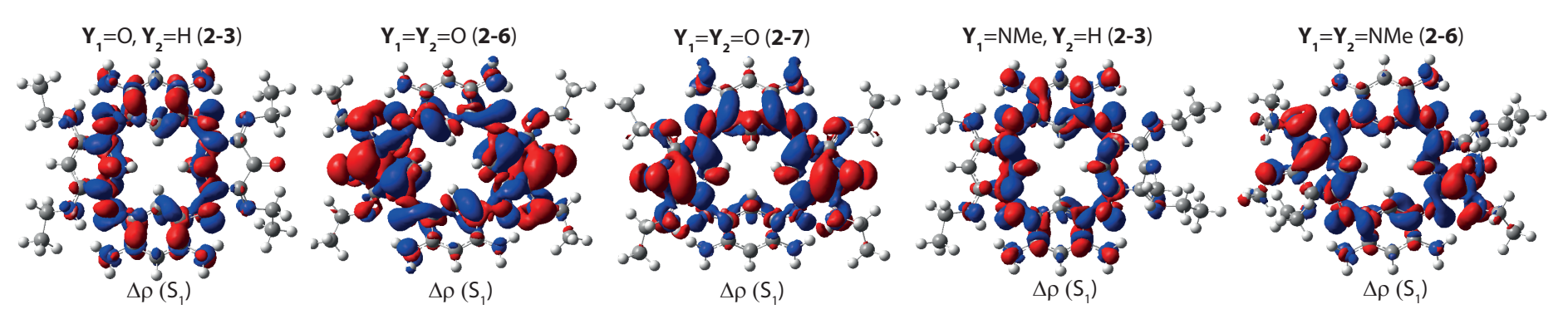

Fig. 14 Electronic density difference corresponding to the first absorption band of the doubly-deprotonated $\mathbf{Y}$-substituted ACPs with: (from left to right) $\mathbf{Y}_{1}=\mathrm{O}$ and $\mathbf{Y}_{2}=\mathrm{H}(\mathbf{2}-\mathbf{3}), \mathbf{Y}_{1}=\mathbf{Y}_{2}=\mathrm{O}(\mathbf{2}-\mathbf{6}), \mathbf{Y}_{1}=\mathbf{Y}_{2}=\mathrm{O}(\mathbf{2 - 7}), \mathbf{Y}_{1}=\mathrm{NMe}$ and $\mathbf{Y}_{2}=\mathrm{H}(\mathbf{2}-\mathbf{3})$, and $\mathbf{Y}_{1}=\mathbf{Y}_{2}=\mathrm{NMe}$ (2-76). See caption of Figure 9 for more details. 
plane of the cyanine moiety, considerably reducing its impact. In contrast, for groups bonding at $\mathbf{Y}$ through double bonds (here $=\mathrm{O}$ and $=\mathrm{NMe}$ ), larger differences with respect to the unsubstituted ACP are foreseen, with interestingly different effects for the keto and imino derivatives. Indeed, placing imino groups induces strong structural distortions of the macrocycle which counterbalances the electronic effects leading to relatively moderate variations of the optical signatures. In contrast, for keto compounds, very large differences in the absorption could be obtained, i.e., a strong bathochromic shift once (at least) one of the external amino groups of the substituted-subunit is deprotonated. This latter outcome pointed out a very interesting feature, that is, a strong acidochromism, occurring in keto-derivatives. In contrast, in the unsubstituted ACP, acidochromism is trifling. This work therefore stands as an additional proof of the interest of exploring the rich chemistry of azacalixphyrins.

\section{Acknowledgments}

C. A. acknowledges the support of the Agence Nationale de La Recherche (ANR - EMA grant) for her PhD grant. C. A. and D. J. are indebted to X. Blase and I. Duchemin for providing access to the Fiesta code. The authors thank the Région des Pays de la Loire for the LUMOMAT RFI project. This work was performed using resources of the GENCI-CINES/IDRIS, of the CCIPL ("Centre de Calcul Intensif des Pays de la Loire"), of local Troy (Nantes) clusters.

\section{References}

1 G. de la Torre, C. G. Claessens and T. Torres, Chem. Commun., 2007, 2000-2015.

2 T. D. Lash, Org. Biomol. Chem., 2015, 13, 7846-7878.

3 A. Ito, J. Mater. Chem. C, 2016, 4, 4614-4625.

4 T. Tanaka and A. Osuka, Chem. Soc. Rev., 2015, 44, 943-969.

5 T. D. Lash, Chem. Rev., 2017, 117, 2313-2446.

6 R. Paolesse, S. Nardis, D. Monti, M. Stefanelli and C. Di Natale, Chem. Rev., 2017, 117, 2517-2583.

7 B. Szyszko, M. J. Białek, E. Pacholska-Dudziak and L. LatosGrażyński, Chem. Rev., 2017, 117, 2839-2909.

8 H. Lu and N. Kobayashi, Chem. Rev., 2016, 116, 6184-6261.

9 Z. Chen, M. Giorgi, D. Jacquemin, M. Elhabiri and O. Siri, Angew. Chem. Int. Ed., 2013, 52, 6250-6254.

10 G. Marchand, A. D. Laurent, Z. Chen, O. Siri and D. Jacquemin, J. Phys. Chem. A, 2014, 118, 8883-8888.

11 G. Marchand, P. Giraudeau, Z. Chen, M. Elhabiri, O. Siri and D. Jacquemin, Phys. Chem. Chem. Phys., 2016, 18, 96089615.

12 G. Marchand, O. Siri and D. Jacquemin, Phys. Chem. Chem. Phys., 2016, 18, 27308-27316.

13 Z. Chen, R. Haddoub, J. Mahé, G. Marchand, D. Jacquemin, J. Andeme Edzang, G. Canard, D. Ferry, O. Grauby, A. Ranguis and O. Siri, Chem. Eur. J., 2016, 22, 17820-17832.

14 G. Marchand, O. Siri and D. Jacquemin, Phys. Chem. Chem. Phys., 2017, 19, 15903-15913.

15 S. Dähne and D. Leupold, Angew. Chem. Int. Ed., 1966, 5, 984-993.

16 O. Siri, P. Braunstein, M.-M. Rohmer, M. Bénard and R. Welter, J. Am. Chem. Soc., 2003, 125, 13793-13803.
17 S. Pascal, L. Lavaud, C. Azarias, G. Canard, M. Giorgi, D. Jacquemin and O. Siri, Mater. Chem. Front., 2018, in press, 10.1039/C8QM00171E.

18 S. Pascal, A. Haefele, C. Monnereau, A. Charaf-Eddin, D. Jacquemin, B. Le Guennic, C. Andraud and O. Maury, J. Phys. Chem. A, 2014, 118, 4038-4047.

19 M. J. Frisch, G. W. Trucks, H. B. Schlegel, G. E. Scuseria, M. A. Robb, J. R. Cheeseman, G. Scalmani, V. Barone, G. A. Petersson, H. Nakatsuji, X. Li, M. Caricato, A. V. Marenich, J. Bloino, B. G. Janesko, R. Gomperts, B. Mennucci, H. P. Hratchian, J. V. Ortiz, A. F. Izmaylov, J. L. Sonnenberg, D. WilliamsYoung, F. Ding, F. Lipparini, F. Egidi, J. Goings, B. Peng, A. Petrone, T. Henderson, D. Ranasinghe, V. G. Zakrzewski, J. Gao, N. Rega, G. Zheng, W. Liang, M. Hada, M. Ehara, K. Toyota, R. Fukuda, J. Hasegawa, M. Ishida, T. Nakajima, Y. Honda, O. Kitao, H. Nakai, T. Vreven, K. Throssell, J. A. Montgomery, Jr., J. E. Peralta, F. Ogliaro, M. J. Bearpark, J. J. Heyd, E. N. Brothers, K. N. Kudin, V. N. Staroverov, T. A. Keith, R. Kobayashi, J. Normand, K. Raghavachari, A. P. Rendell, J. C. Burant, S. S. Iyengar, J. Tomasi, M. Cossi, J. M. Millam, M. Klene, C. Adamo, R. Cammi, J. W. Ochterski, R. L. Martin, K. Morokuma, O. Farkas, J. B. Foresman and D. J. Fox, Gaussian 16 Revision A.03, 2016, Gaussian Inc. Wallingford CT.

20 T. M. Krygowski and H. Szatylowicz, ChemTexts, 2015, 1, 12.

21 P. v. R. Schleyer, C. Maerker, A. Dransfeld, H. Jiao and N. J. R. van Eikema Hommes, J. Am. Chem. Soc., 1996, 118, 63176318.

22 Z. Chen, C. S. Wannere, C. Corminboeuf, R. Puchta and P. v. R. Schleyer, Chem. Rev., 2005, 105, 3842-3888.

23 C. Adamo and V. Barone, J. Chem. Phys., 1999, 110, 61586170.

24 M. Ernzerhof and G. E. Scuseria, J. Chem. Phys., 1999, 110, 5029-5036.

25 Y. Zhao and D. G. Truhlar, Acc. Chem. Res., 2008, 41, 157-167.

26 T. Yanai, D. P. Tew and N. C. Handy, Chem. Phys. Lett., 2004, 393, 51-56.

27 J. Tomasi, B. Mennucci and R. Cammi, Chem. Rev., 2005, 105, 2999-3094.

28 R. Cammi and B. Mennucci, J. Chem. Phys., 1999, 110, 98779886.

29 M. Cossi and V. Barone, J. Chem. Phys., 2001, 115, 47084717.

30 A. Dreuw and M. Wormit, WIREs Comput. Mol. Sci., 2015, 5, 82-95.

31 O. Christiansen, H. Koch and P. Jørgensen, Chem. Phys. Lett., 1995, 243, 409-418.

32 TURBOMOLE V6.6 2014, a development of University of Karlsruhe and Forschungszentrum Karlsruhe GmbH, 19892007, TURBOMOLE GmbH, since 2007; available from http: / / www . turbomole.com (accessed 13 June 2016).

33 X. Blase, I. Duchemin and D. Jacquemin, Chem. Soc. Rev., 2018, 47, 1022-1043.

34 X. Blase, C. Attaccalite and V. Olevano, Phys. Rev. B, 2011, 83, 115103.

35 M. Valiev, E. J. Bylaska, N. Govind, K. Kowalski, T. P. Straatsma, H. J. J. Van Dam, D. Wang, J. Nieplocha, E. Apra, T. L. Windus and W. A. de Jong, Comput. Phys. Commun., 2010, 181, 1477-1489.

36 D. Jacquemin, I. Duchemin and X. Blase, J. Chem. Theory Comput., 2015, 11, 5340-5359. 
37 P. Boulanger, D. Jacquemin, I. Duchemin and X. Blase, J. Chem. Theory Comput., 2014, 10, 1212-1218.

38 L. Goerigk and S. Grimme, J. Phys. Chem. A, 2009, 113, 767776.

39 A. D. Laurent and D. Jacquemin, Int. J. Quantum Chem., 2013, 113, 2019-2039.
40 To see if this unusual behavior is related to range-separation, we have computed the PCM-TD-DFT values with the M06 family of global hybrids. For this family, the wavelength of the first significantly dipole-allowed transition increases as well with increasing exact exchange: M06-L(0\%): $834 \mathrm{~nm}$, M06(27\%): $838 \mathrm{~nm}$, M06-2X(54\%): $858 \mathrm{~nm}$, and M06HF(100\%): $995 \mathrm{~nm}$. 


\section{Graphical Abstract}

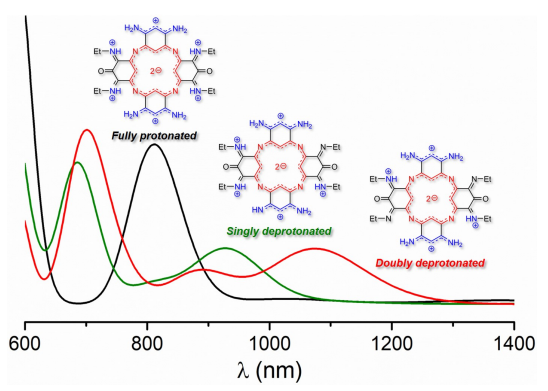

